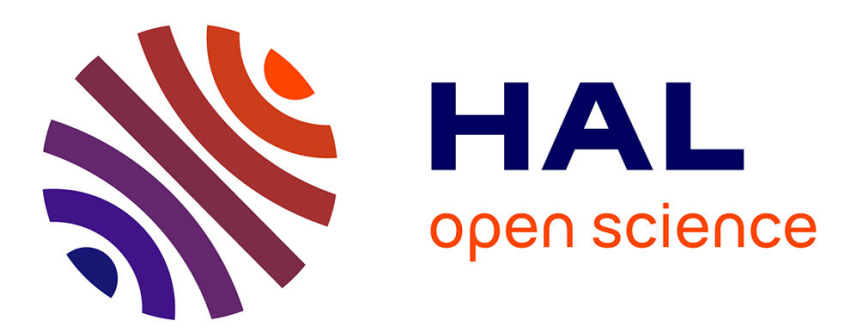

\title{
Surface modifications of nanodiamonds and current issues for their biomedical applications \\ Jean-Charles Arnault
}

\section{To cite this version:}

Jean-Charles Arnault. Surface modifications of nanodiamonds and current issues for their biomedical applications. Yang, Nianjun. Novel Aspects of Diamond - From Growth to Applications, 121 (Chapter 4), Springer Verlag, pp.85-122, 2015, Topics in Applied Physics, ISBN 978-3-319-09833-3, ISBN 9783-319-09834-0 (eBook). 10.1007/978-3-319-09834-0-4 . cea-01818478

\section{HAL Id: cea-01818478 https://hal-cea.archives-ouvertes.fr/cea-01818478}

Submitted on 17 Jan 2020

HAL is a multi-disciplinary open access archive for the deposit and dissemination of scientific research documents, whether they are published or not. The documents may come from teaching and research institutions in France or abroad, or from public or private research centers.
L'archive ouverte pluridisciplinaire HAL, est destinée au dépôt et à la diffusion de documents scientifiques de niveau recherche, publiés ou non, émanant des établissements d'enseignement et de recherche français ou étrangers, des laboratoires publics ou privés. 


\title{
Chapter 4 \\ Surface Modifications of Nanodiamonds and Current Issues for Their Biomedical Applications
}

\author{
Jean-Charles Arnault \\ CEA, LIST, Diamond Sensors Laboratory, 91191 Gif Sur Yvette, France e-mail: jean-charles.arnault@cea.fr
}

\begin{abstract}
Combining numerous unique assets, nanodiamonds are promising nanoparticles for biomedical applications. The present chapter focuses on the current knowledge of their properties. It shows how the control of their surface chemistry governs their colloidal behavior. This allows a fine tuning of their surface charge. Developments of bioapplications using nanodiamonds are summarized and further promising challenges for biomedicine are discussed.
\end{abstract}

\subsection{Introduction}

Nanoparticles (NPs) are currently designed and developed for nanomedecine applications which constitute an emerging research field [1]. Among the main stakes, cancer therapy expands with three main paradigms: drug delivery, biomarkers for diagnosis and therapeutics.

The main interest to use NPs for drug delivery is the ability to target cancer cells. Indeed, some tumors present a higher vascularisation which could favor a passive targeting of NPs via the EPR effect (Enhanced Permeability and Retention) [2]. The targeting can also be active when a specific grafting of NPs with specific markers is performed [3]. The use of NPs can enhance the treatment efficiency allowing the delivery of higher doses while it reduces significantly side effects. Polymeric NPs

[4] and liposomes are currently the most used NPs to encapsulate drugs. The polymer degradation permits their progressive delivery.

Second, NPs can also act as biomarkers for tumor imaging or tracking via their optical properties as quantum dots [5] or gold NPs via surface plasmon resonance [6]. However, some of these luminescent probes are limited either by their photostability or their cytotoxicity. Inorganic NPs can be used as contrast agents for magnetic resonance imaging [7, 8]. Lastly, $\mathrm{C}^{14}$ grafting on carbon nanotubes wasreported conferring radiolabeling properties for exploration of the in vivo biodistribution and pharmacokinetics [9].

Third, NPs can have therapeutic roles if they could be activated by an external stimulus. For example, under an external magnetic field, metallic NPs can generate temperature elevation called hyperthermia leading to cell death [10]. This activation can also be performed thanks to optical properties i.e. phototherapy for graphene oxide nanosheets $[11,12]$ or metallic NPs [13]. Efficiency of radiotherapy treatments can be enhanced by coupling with NPs. This constitutes a promising way to treat resistant tumors. Such approach may permit the delivery of lower doses for the same efficacy. A radiosensitization effect can be obtained under irradiation producing Reactive Oxygen Species (ROS) in cells. For this application, gold [14], platinum [15] or rare earths [16] NPs are used due to their high ratio of Auger electrons generated under irradiation.

The current trend which associates therapeutic and diagnostic properties is called theranostics [17, 18]. For this purpose, hybrid nanoparticles are designed combining properties of their core and shell: for example, superparamagnetic NPs embedded in mesoporous silica [19] or gold NPs in liposomes [20].

Nanodiamonds (NDs) constitute promising NPs for biomedicine applications. They possess many unique assets. They are scalable with sizes ranging from $100 \mathrm{~nm}$ down to $5 \mathrm{~nm}$. One can expect the elimination by kidney for the smaller NDs (diameter lower than $6 \mathrm{~nm}$ ) [21]. Nanodiamonds are also available in large quantities at reasonable prices $(<\$ 1 / \mathrm{g})$. Several studies reported their very low toxicity related to the high chemical inertia of diamond [22-25]. Recent research demonstrates they are even biocompatible with advantages for drug delivery or fluorescence labels $[26,27]$. NDs enable covalent grafting of various chemical moieties on their surfaces [28] resulting in stable colloidal aqueous solutions. Covalent chemistry works similar way on NDs as for organics.

Their surface charge can be tuned allowing the electrostatic adsorption of biomolecules such as siRNA [27, 29]. They have been used for drug delivery applications [30-32].

Moreover, NDs can act as biomarkers for diagnosis. Indeed, color centers can be generated from nitrogen present in the diamond core by electron or helium irradiation [33] followed by a thermal annealing. Under green illumination, produced nitrogen-vacancy (NV) centers emits in the red wavelength region, they are highly photostable presenting neither photoblinking nor photobleaching [34].

Potential therapeutic behaviors of NDs related to their specific surface properties are currently under investigation.

Investigations of nanodiamonds for biomedical applications started quite recently. Numerous parameters remain partially controlled such as their different surface chemistry, their surface charge, their colloidal stability and the role 
of facets in their surface properties. The present chapter summarizes the current knowledge and the assets of NDs for nanomedecine. First, the different ways to produce nanodiamonds will be briefly presented (Part 4.2). Then, the characterization tools of their core and surface will be detailed focusing on the most relevant characterization methods (Part 4.3). The main surface modifications performed using different approaches (chemical, physical or plasma treatments) will be reviewed (Part 4.4). Electronic properties of modified nanodiamonds will be presented as well as their colloidal behaviors in water (Part 4.5). Finally, main assets of NDs for biomedical applications will be discussed before giving some future promising challenges (Part 4.6).

\subsection{Production of Nanodiamonds}

According to thermodynamics, graphite is the stable carbon form at ambient conditions while diamond is metastable $[35,36]$. Since 1950 s, synthetic diamond can be obtained by high pressure high temperature (HPHT) method using hydraulic press which reproduces the conditions of natural diamond formation [37]. In 1980s, chemical vapor deposition (CVD) diamond was discovered and developed [38]. Different techniques are presently used to fabricate nanodiamonds: either NDs could be obtained by milling of HPHT/CVD diamond or NDs could be synthetized using explosives or laser ablation of graphite precursors [39, 40].

Monocrystalline nanodiamonds with size down to $20 \mathrm{~nm}$ can be obtained by ball milling of micron-sized HPHT diamonds. High Resolution Transmission Electron Microscopy (HRTEM) revealed faceted shapes with sharp edges corresponding to fractured crystallographic planes. In few cases, quasi spherical nanodiamonds smaller than $10 \mathrm{~nm}$ were obtained by HPHT milling [41, 42]. More recently, 70-80 nm nanodiamonds were also produced from polycrystalline CVD diamond by bead assisted sonic disintegration (BASD) [43].

Alternatively, nanodiamonds could be synthetized by several dynamic processes from molecules of explosives and different carbon precursors [44] (Fig. 4.1). Three methods could be distinguished: the direct transformation of graphite by an external shock wave, the detonation of graphite mixed with explosives (hexogen/RDX) or the detonation of high energy explosives (TNT/hexogen/RDX). For detonation synthesis, the key parameters governing the yield of nanodiamonds are the heat capacity, the content and the reactivity of the medium, the cooling of detonation products [45]. Nanodiamonds produced by detonation usually exhibit smaller diameters ranging typically from 2 to $20 \mathrm{~nm}$. Several models were proposed to explain their formation by detonation synthesis [45]. More details about ND synthesis by detonation methods could be found in previous reports [45, 46].

After detonation, the collected soot contains metals, metal oxides and carbides. In addition to carbon, its elemental composition reveals hydrogen, nitrogen and oxygen species. Indeed, nitrogen is initially present in HPHT diamond and in explosives used in the detonation synthesis. In most cases, a-C and/or $\mathrm{sp}^{2}$ carbon are surrounding the diamond core. Detonation NDs are extracted after purification procedures using liquid oxidants to remove nondiamond carbon. Indeed, diamond and non-diamond carbon have different stability to oxidants. The efficiency of an ozone treatment was also reported to eliminate the non-diamond carbon [46]. Then, liquid-phase oxidation using $\mathrm{HCl}$ or other high boiling acids is applied to eliminate the non-carbon impurities. The resulting surface chemistry of detonation nanodiamonds will be described in the next paragraph (Part 4.3).

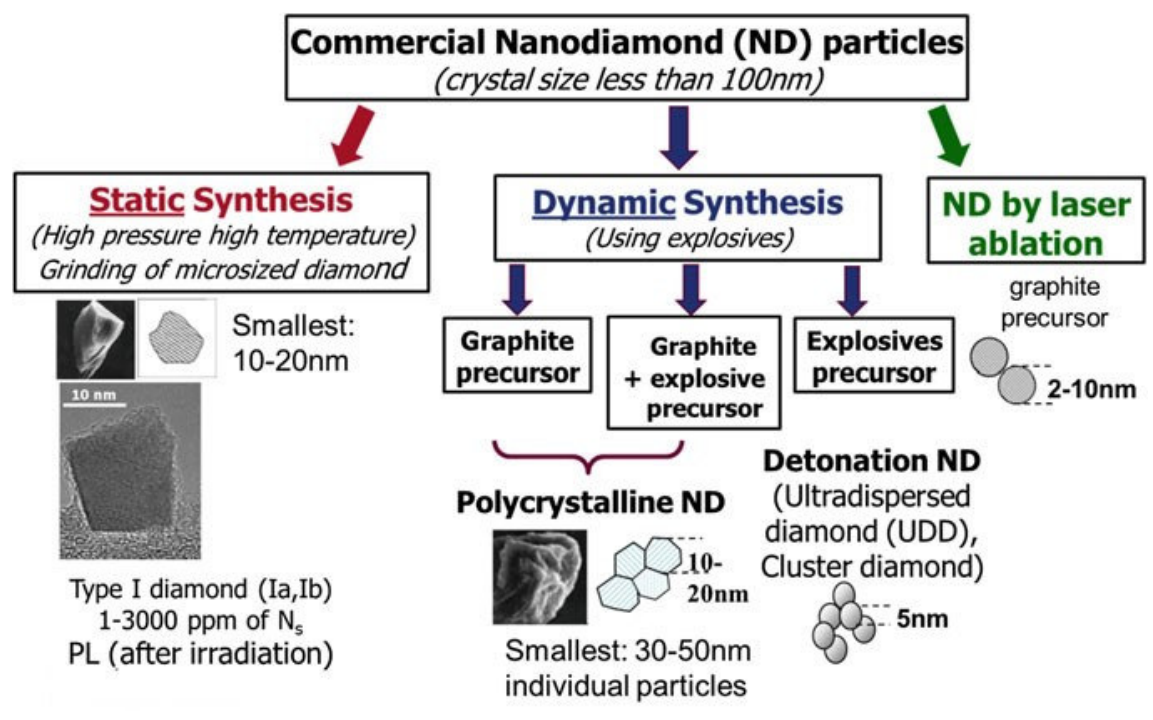

Fig. 4.1 The different natures of NDs [44] courtesy of O. Shenderova, International Technology Center, USA 
Diamond nanoparticles have been classified according to their size [44]. Nanocrystalline particles (10-100 nm) could be either monocrystalline (HPHT milling) or polycrystalline after shock-wave compression of graphite or detonation of carbon/explosives mixture. Ultrananocrystalline NDs $(2-10 \mathrm{~nm})$ are mainly produced by detonation or laser ablation. Smallest particles behave to the family of diamondoids. Higher diamondoids (1-2 nm) are extracted from petroleum with hydrogen termination [47]. The smallest specie of cubic diamond, the adamantane, contains 10 carbon atoms $\left(\mathrm{C}_{10} \mathrm{H}_{16}\right)$.

\subsection{Characterization Tools}

Depending on their synthesis methods (Part 4.2), nanodiamonds can behave different core-shell structures, morphologies and surface chemistry. Experimental and theoretical works reported multi-shell structures based on a diamond core which could be surrounded by defective diamond, amorphous carbon and/or several onion like outershells $[48,49]$. According to calculations, this structure constitutes the most stable energetic form for $\mathrm{sp}^{3}$ nanometric clusters [50]. Characterization methods were developed to specifically probe the crystalline structure as well as the chemical composition of diamond core, outer shells and surface of nanodiamonds. The most relevant techniques to assess these characteristics are presented in Table 4.1.

Table 4.1 Characterization tools of nanodiamonds

\begin{tabular}{l|l}
\hline \multicolumn{2}{l}{ Diamond core } \\
\hline Particle size, crystalline structure & HRTEM, XRD, SAXS \\
\hline Morphology and shape & HRTEM \\
\hline Structural defects & HRTEM \\
\hline Chemical impurities & XPS, EELS/STEM \\
\hline Local environment & NEXAFS, ESR, NMR, ELNES \\
\hline NV centers & Time resolved PL, confocal PL \\
\hline Outer shells and surface & \\
\hline a-C, sp ${ }^{2}$ carbon & Raman, HRTEM, XRD, XPS \\
\hline Surface chemistry and grafting & FTIR, XPS, TDMS \\
\hline
\end{tabular}

\subsubsection{Diamond Core}

Its crystalline structure can be accurately investigated by high resolution transmission electron microscopy (HRTEM) in bright field mode. The signature of diamond lattice is also confirmed in the diffraction mode. Moreover, structural defects as twins or dislocations within diamond lattice can be resolved especially for nanodiamonds produced by detonation method [51]. The spherical or faceted shape of nanodiamonds which could greatly influence their reactivity could be characterized at the nanoscale using HRTEM. As an illustration, (111) facets with (100)-type truncations were identified even for detonation NDs of $2 \mathrm{~nm}$ [51] (Fig. 4.2). More recently, modern HRTEM instruments were developed to operate at low electron energy down to $40 \mathrm{keV}$. Lens aberrations are reduced allowing image resolution down to $50 \mathrm{pm}$ [52]. In these experimental conditions, the graphitization of NDs which may occur under electron beam is completely avoided. Diamond core structure and size of nanodiamonds can be also investigated by X-ray Diffraction (XRD) [53] or Small Angle X-ray Scattering (SAXS) [54]. Contrary to XRD which is limited by diffraction effects leading to physical broadening, SAXS give access to sizes very close to HRTEM. Size distributions can even be extracted from SAXS data assuming a shape for NDs.

The concentration of chemical impurities (N, O, H, metals remaining from synthesis) within diamond core and their location in the diamond lattice is another important issue. For example, the nitrogen presence could confer optical properties to nanodiamonds via the formation of luminescent nitrogen vacancy (NV) centers. Atomic concentrations of impurities (excepted hydrogen) could be assessed from X-ray Photoemission Spectroscopy (XPS). Typically, the detection limit for oxygen and nitrogen is close to 0.5 at \% [55]. Very few techniques such as SIMS or NMR are sensitive to hydrogen. During synthesis of nanodiamonds, hydrogen is likely to be inserted into diamond core. Indeed, hydrogen diffusion was previously reported in bulk diamond [56]. There is a crucial need to probe hydrogen into diamond core because it could confer new properties to nanodiamonds. 


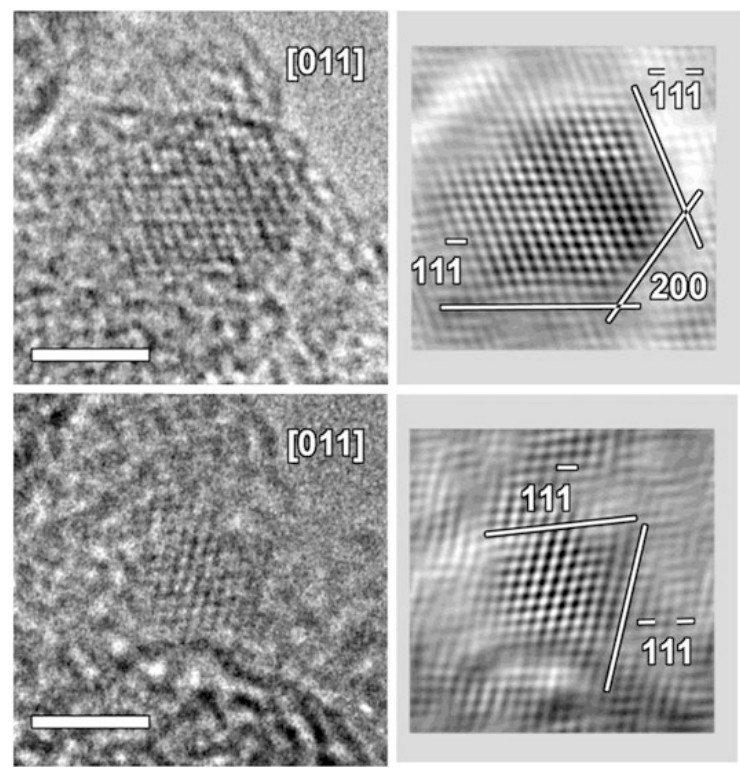

Fig. 4.2 HRTEM pictures of detonation nanodiamonds, scale bar $2 \mathrm{~nm}$ [51] courtesy of S. Turner, University of Antwerp

Electron spin resonance (ESR) is the most sensitive method to detect nitrogen $\left(10^{12}\right.$ spins $)$ [57, 58]. Indeed, single nitrogen in substitution in diamond lattice is paramagnetic [59]. Core loss electron energy loss spectroscopy (EELS) profiles can also probe light elements as nitrogen, oxygen, boron or carbon. Energy loss near edge structures (ELNES) technique provides a signature of the local binding of impurities. For example, the tetrahedral configuration can be deduced from the nitrogen $\mathrm{K}$ edge structure [51, 60]. Recent work shows this technique permits to confirm the tetrahedral insertion of boron atoms in diamond leading to p-doping [61, 62]. EELS combined with scanning TEM (STEM) can even provide mapping or profiles of impurities with an atomic resolution [63-65]. Nearedge X-ray absorption fine structure (NEXAFS) technique could probe the local bonding environment [66]. Nuclear Magnetic Resonance permits to probe hydrogen $\left({ }^{1} \mathrm{H}\right)$, nitrogen $\left({ }^{15} \mathrm{~N}\right)$ and carbon $\left({ }^{13} \mathrm{C}\right)$ spins [67].

Photoluminescence (PL) spectroscopy can reveal signature of structural imperfection of diamond lattice (defects, impurities). Luminescent NV centers composed by a nitrogen atom in substitution combined with a neighbouring vacancy are characterized by PL. Under excitation at $531 \mathrm{~nm}$, emission wavelengths at 575 and $638 \mathrm{~nm}$ are detected corresponding to different charge states $\mathrm{NV}^{0}$ and $\mathrm{NV}^{-}$, respectively [57]. NV centers exhibit a high stability without any photoblinking or photobleaching. Recently, the influence of NDs surface chemistry on NV luminescence was shown, especially a quenching of the $\mathrm{NV}^{-}$luminescence when nanodiamond surface is hydrogenated [68].

\subsubsection{Outer Shells and Surface Chemistry}

Surface chemistry of nanodiamonds is strongly dependent on their synthesis method and the purification treatments (Part 4.2). For pristine NDs, the diamond core is usually coated with non $\mathrm{sp}^{3}$ carbon. These carbon outer-shells could be structured as onion-like shells [69] or could exhibit an amorphous structure $(\mathrm{a}-\mathrm{C})$ [70]. The nature of outer shells must be well characterized because it strongly affects the surface reactivity of nanodiamonds. Raman spectroscopy gives access to composition and structure for bulk carbon phases [71]. A signature at $1332 \mathrm{~cm}^{-1}$ is obtained for diamond while D and $\mathrm{G}$ bands at 1410 and $1590 \mathrm{~cm}^{-1}$ originate from amorphous and graphitic carbon, respectively. Nevertheless, a specific Raman interpretation is needed for detonation nanodiamonds (size lower than $6 \mathrm{~nm}$ ) taking into account a phonon confinement leading to a downshift and an asymmetry of the diamond Raman peak [72, 73]. Some features like the one located at $1640 \mathrm{~cm}^{-1}$ are still a matter of debate [36]. XPS is also sensitive to $\mathrm{sp}^{2}$ and $\mathrm{sp}^{3}$ hybridization of carbon, it was recently used to monitor the surface graphitization of nanodiamonds [55]. However, artefacts due to nanomaterials especially the high fraction of surface versus bulk must be taken into account in the data interpretation [74, 75]. Auger Electron Spectroscopy (AES) is even more sensitive to carbon hybridization because two valence electrons are involved in the C KVV transition [70]. Using low loss EELS, a-C or graphite could also be discriminated [76]. HRTEM imaging provides the structure of the outer-shells at atomic scale [51, 75].

After their synthesis, nanodiamonds underwent oxidizing treatments to clean metallic impurities (Part 4.2). This leads to a heterogeneous surface chemistry involving different carbon-oxygen groups. To investigate the surface chemistry of nanodiamonds after purification or functionalization, Fourier Transformed InfraRed (FTIR) Spectroscopy is a powerful technique as diamond core is transparent to IR. It is sensitive to the vibrations of carbonhydrogen $\left(\mathrm{C}-\mathrm{H}_{\mathrm{x}}\right)[77]$ and the different carbon-oxygen bonds $(\mathrm{O}-\mathrm{H}, \mathrm{C}-\mathrm{O}, \mathrm{C}-\mathrm{O}-\mathrm{C}, \mathrm{C}=\mathrm{O})$. Moreover, it could detect 
$\mathrm{C}-\mathrm{N}$ or $\mathrm{N}-\mathrm{H}$ vibrations [78]. Although FTIR is usually done in transmission mode, a diamond-coated ATR prism for infrared absorption spectroscopy was recently used to characterize surface-modified diamond nanoparticles [79]. Raman spectroscopy performed under UV light could provide signature of $\mathrm{C}-\mathrm{H}$ surface bonds for hydrogenated diamond surface $[80,81]$. High resolution electron energy loss spectroscopy (HREELS) can probe the surface bonds of the first atomic plane with a resolution of $5 \mathrm{meV}$. It was recently used to characterize the surface chemistry of hydrogenated nanodiamonds [76]. NMR experiments are sensitive to ozone-treated or hydroxylated nanodiamonds as well as functionalization with fluorine $\left({ }^{19} \mathrm{~F}\right)[67]$.

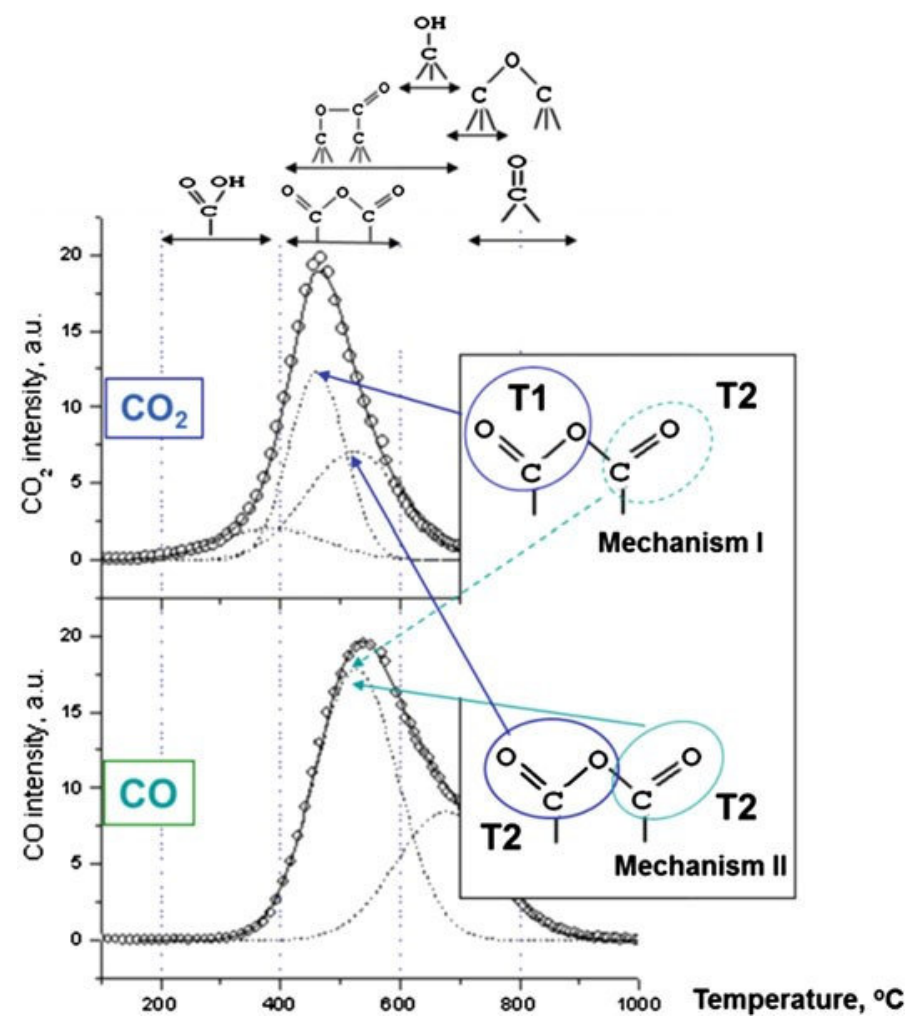

Fig. 4.3 Two possible desorption mechanisms of anhydrides on ozone treated NDs for two temperatures from TDMS [46] courtesy of O. Shenderova, International Technology Center, USA

Finally, as an indirect surface chemistry probe, let cite the thermal desorption mass spectrometry (TDMS) analysis which is a continuous measurement of the mass spectra of gases released from a sample under programmed heating [82, 83]. This technique permits a fine identification of functional groups according to their specific desorption temperature and gives information concerning their thermal stability. As an illustration, TDMS spectra can help to understand the anhydrides desorption from ozone purified NDs [46] (Fig. 4.3).

\subsection{Surface Modifications of Nanodiamonds}

Nanodiamond surface appears highly heterogeneous exhibiting different carbonoxygen functional groups (ether, hydroxyl, carbonyl, carboxyl,...), a-C and/or $\mathrm{sp}^{2}$ carbon. This scattered surface chemistry is mainly related to purification steps (Part 4.3). Surface treatments were developed to get homogeneous chemistry allowing more efficient further graftings [28] either by chemical, thermal or plasma approaches. In addition, these controlled surface chemistries help to stabilize $\mathrm{ND}_{\mathrm{S}}$ in aqueous suspension limiting aggregation (Part 4.5). Indeed, detonation NDs tend to aggregate while many applications require isolated primary NDs [36]. Milling or BASD procedures [84] were successfully applied for deaggregation. Nevertheless, these treatments can induce either chemical contaminations or surface graphitization. The efficiency of surface treatments such as oxidation in air [85] or plasma hydrogenation [86] was reported. Indeed, tuning the surface chemistry can confer intrinsic electronic properties to NDs surface having consequences on their aggregation and colloidal behavior (Part 4.5). Thermal treatments permit to create hybrid nanoparticles constituted by a diamond core surrounded by $\mathrm{sp}^{2}$ reconstructions [75]. Table 4.2 presents the major reported terminations and their uses. 
Table 4.2 Surface terminations of NDs vs treatments

\begin{tabular}{|c|c|c|c|}
\hline \multicolumn{2}{|c|}{ Surface terminations } & Treatments & Objectives \\
\hline \multirow{2}{*}{\multicolumn{2}{|c|}{ Hydrogenated }} & $\mathrm{H}_{2}$ plasma $[70,87]$ & \multirow{2}{*}{$\begin{array}{l}\text { positive ZP with SCL } \\
\text { grafting }\end{array}$} \\
\hline & & annealing at $500{ }^{\circ} \mathrm{C}$ under $\mathrm{H}_{2}$ [88] & \\
\hline \multirow[t]{7}{*}{ Oxidized } & \multirow[t]{3}{*}{ Carboxylated } & different acid treatments [28] & \multirow{3}{*}{$\begin{array}{l}\text { negative ZP } \\
\text { disaggregation } \\
\text { grafting of peptides }\end{array}$} \\
\hline & & air annealing at $400-430^{\circ} \mathrm{C}$ [89] & \\
\hline & & $\begin{array}{l}\text { ozone treatment at } 150-200{ }^{\circ} \mathrm{C} \\
{[46]}\end{array}$ & \\
\hline & \multirow[t]{4}{*}{ Hydroxylated } & borane reduction [90] & \multirow{4}{*}{$\begin{array}{l}\text { grafting } \\
\text { silanization }\end{array}$} \\
\hline & & Fenton reagent [91] & \\
\hline & & milling with beads $[69,92]$ & \\
\hline & & photochemistry [93] & \\
\hline \multirow{2}{*}{\multicolumn{2}{|c|}{ Fluorinated }} & $\mathrm{F}_{2} / \mathrm{H}_{2}$ exposure at $150-470{ }^{\circ} \mathrm{C}[94]$ & \multirow[t]{2}{*}{ grafting } \\
\hline & & $\mathrm{CF}_{4}$ plasma [95] & \\
\hline \multirow{2}{*}{\multicolumn{2}{|c|}{ Aminated }} & $\begin{array}{l}\text { Cl-term NDs in gaseous ammonia } \\
{[96]}\end{array}$ & \multirow[t]{2}{*}{$\begin{array}{l}\text { positive ZP } \\
\text { grafting }\end{array}$} \\
\hline & & $\begin{array}{l}\text { covalent grafting of amine deriva- } \\
\text { tive }[84,97,98]\end{array}$ & \\
\hline \multirow{2}{*}{\multicolumn{2}{|c|}{ Surface graphitised }} & $\begin{array}{l}\text { annealing at } 750{ }^{\circ} \mathrm{C} \text { under vacuum } \\
{[55,99,100]}\end{array}$ & \multirow{2}{*}{$\begin{array}{l}\text { positive ZP by oxygen } \\
\text { hole doping } \\
\text { hybrid properties }\end{array}$} \\
\hline & & long beads milling [101] & \\
\hline
\end{tabular}

\subsubsection{Surface Hydrogenation of Nanodiamonds}

The aim is to generate homogeneous $\mathrm{C}-\mathrm{H}$ bonds at nanodiamond surface. Hydrogenated intrinsic diamond surface behave specific electronic properties characterized by a negative electron affinity (NEA) [102]. After air exposure, it presents a surface conductivity by a transfer doping involving adsorbed species [103]. Hydrogen atoms may also diffuse into the diamond lattice where they are preferentially trapped on structural defects or chemical impurities [56].

Annealing treatments under $\mathrm{H}_{2}$ flow at $850-900{ }^{\circ} \mathrm{C}$ were reported for diamond particles bigger than $100 \mathrm{~nm}[104$, 105]. Nevertheless, this temperature range is very close to the one leading to graphitization for smaller nanodiamonds. Recent reports demonstrated that surface graphitization started at $750{ }^{\circ} \mathrm{C}$ for $5 \mathrm{~nm}$ detonation NDs $[55,99]$. Similar treatments performed at lower temperature (typically $500{ }^{\circ} \mathrm{C}$ ) seem to produce an efficient deaggregation of detonation NDs after centrifugation. Nevertheless, HRTEM reveals that onion like shells are still present after the annealing [88]. FTIR shows a partial coverage by $\mathrm{C}-\mathrm{H}$ bonds conferring a hydrophobic behavior to treated nanodiamonds $[88,106]$. These results suggest hydrogen is more likely bonded to $\mathrm{sp}^{2}$ carbon. Another method for hydrogenation would use organic chemistry with metal catalyst such as $\mathrm{Pd}$, Pt or Ni [107, 108]. However, in that case, catalysts must be further eliminated.

An interesting alternative consists to expose NDs to $\mathrm{H}_{2}$ CVD plasma. Under microwave field or thermal cracking [97, 109], dihydrogen molecules are efficiently dissociated into atomic hydrogen. This specie has a high reactivity towards carbon and etches $\mathrm{sp}^{2}$ carbon easier than $\mathrm{sp}^{3}$ carbon [110]. Thus, its interaction with nanodiamonds may allow the loss of non-diamond carbon, the reduction of oxygen species at the surface and the formation of $\mathrm{C} \mathrm{sp}{ }^{3}-\mathrm{H}$ bonds. This surface hydrogenation by CVD plasma is widely used for diamond layers to get hydrogen-terminated boron doped diamond for electrochemistry [111, 112]. Optimized CVD conditions for hydrogenation were determined for detonation nanodiamonds using a Microwave Plasma Chemical vapor Deposition (MPCVD) reactor connected to a UHV set-up [70]. Nanodiamonds were deposited on multilayer Silicon On Insulator (SOI) substrates by drop-casting and samples were analyzed without air exposure. A XPS sequential study allows the monitoring of the oxygen removal after MPCVD exposure. A temperature threshold of $700{ }^{\circ} \mathrm{C}$ is needed to fully remove oxygen from detonation NDs. The hydrogenation efficiency is closely related to the concentration of atomic hydrogen produced in the MPCVD plasma [70].

Proper conditions were then used in a home-made set-up allowing plasma hydrogenation of NDs in powder (Fig. 4.4). Nanodiamonds located in a quartz tube are directly treated in the gas phase [87]. A rotation of this tube allows the exposure of their whole surface to atomic hydrogen. This method is able to treat simultaneously a large amount of NDs (hundreds $\mathrm{mg}$ ) which is a prerequisite to a meaningful surface functionalization. Both HPHT and detonation nanodiamonds which differ by their size and the graphitic shells surrounding the $\mathrm{sp}^{3}$ core, have been hydrogenated.

The surface chemistry of hydrogenated nanodiamonds (H-NDs) was then characterized using XPS and FTIR (Fig. 4.4b). For dried H-NDs, FTIR spectra well exhibit signals located around $2900 \mathrm{~cm}^{-1}$ [87]. These bands have been previously assigned to $\mathrm{C}-\mathrm{H}$ stretching on hydrogenated NDs surfaces [77]. 
The surface reactivity of HPHT H-NDs $(50 \mathrm{~nm})$ was investigated applying several surface modifications [93]: a selective oxidation under UV exposure and functionalization with alkenes and diazonium moieties. These reactions are common on hydrogenated diamond films towards efficient biological functionalizations (DNA, proteins grafting) [113-115] so their use on NDs may also lead to promising developments. However, the chemical mechanisms involved in these grafting routes require specific surface properties, involving charge transfer, which is only provided to the diamond surface by $\mathrm{C}-\mathrm{H}$ hydrogen terminations [116].

(a)

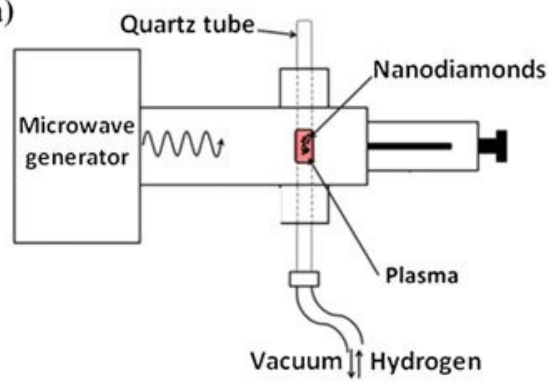

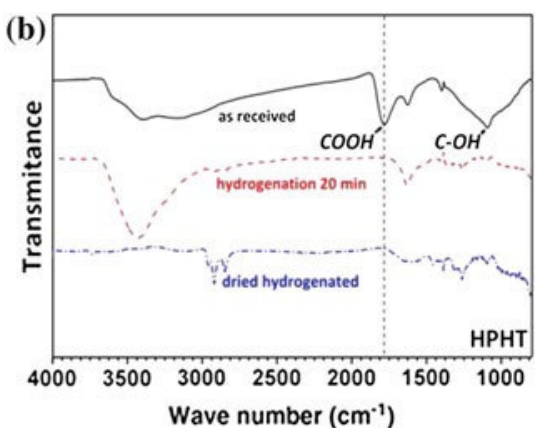

Fig. 4.4 a Set-up for plasma hydrogenation; b FTIR spectra of hydrogenated HPHT NDs [87]

On H-NDs, the oxidation procedure under UV gives rise to a surface hydroxylation as shown by the FTIR bands at 1050 and $3300 \mathrm{~cm}^{-1}$. In addition, a new component appears in the XPS C1s core level [93]. A similar modification of the C1s peak was reported for a diamond surface after UV oxidation [117]. This oxidation treatment appears selective on H-NDs as neither carboxyl nor carbonyl groups were evidenced by XPS or FTIR. An inversion of the Zeta potential was measured after UV oxidation $+30 \mathrm{mV}$ compared to $-45 \mathrm{mV}$ for as received NDs. The origin of this positive Zeta potential will be discussed in the Part 4.5 .

HPHT NDs were also reacted with pure undecylenic acid under $254 \mathrm{~nm}$ UV irradiation. This alkene was chosen for its long alkyl chain and its acid group, both functionalities easily identifiable by FTIR analysis with characteristic structures at $2800 \mathrm{~cm}^{-1}$ and $1700 \mathrm{~cm}^{-1}$ respectively (Fig. 4.5). Furthermore, the vinyl function is evidenced by a peak located around $900 \mathrm{~cm}^{-1}$. For comparison, the same reaction was also conducted on as-received NDs.

The different signatures of undecylenic acid are observed only on the FTIR spectra for hydrogenated HPHT NDs (Fig. 4.5). Moreover, the essential role of UV light in the mechanisms of grafting was demonstrated. On diamond layers, numerous studies report that $\mathrm{C}-\mathrm{H}$ strongly enhances chemical reaction [116] leading to the formation of covalent $\mathrm{C}-\mathrm{C}$ bonds between the diamond surface and the grafted moiety. Indeed, hydrogenated terminations confer to the diamond layers specific electronic surface properties, such as a superficial conductive layer (SCL) [118] and a negative electron affinity

(NEA)

$[102,119]$. The latter is usually highlighted to explain the reactivity of hydrogenated diamond layers towards alkenes, by the mean of photo-excited electrons allowed to propagate out of the diamond into the nearby liquid phase, even with sub-bandgap excitation [120,121]. Authors agree that hydrogen terminations are required for this reaction, and that electron transfer arises from $\mathrm{sp}^{3}$ surfaces and not from grain boundaries and/or $\mathrm{sp}^{2}$ species at the interface. This constitutes a strong indirect proof of the efficiency of hydrogen plasma on NDs.
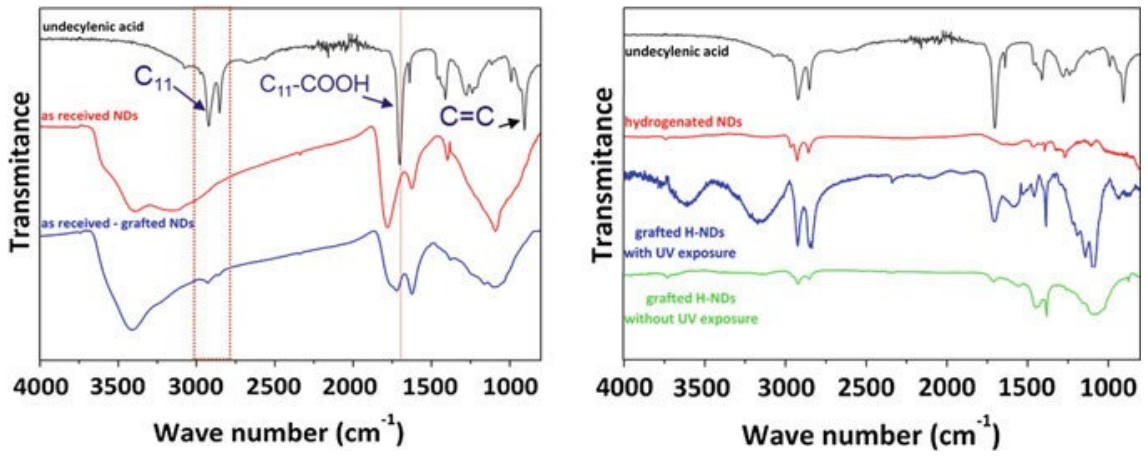

Fig. 4.5 FTIR spectra on (left) as received HPHT NDs (right) HPHT H-NDs [93]

The spontaneous grafting of a diazonium salt on hydrogenated HPHT NDs was also demonstrated [93]. On a diamond surface, this arises from specific electronic properties conferred by $\mathrm{C}-\mathrm{H}$ terminations [122]. The covalent bonding goes through the creation of a phenyl radical by the mean of an electron transfer from the diamond surface to the aryldiazonium salt. This electron transfer is related to the presence of a superficial conductive p-type layer. The commonly accepted mechanism, so-called transfer doping [118] describes an accumulation of holes due to an 
electron transfer from the valence band and a redox couple adsorbed on the surface when the diamond surface is exposed to wet atmosphere or immersed in an electrolyte. This phenomenon is only possible on hydrogenated layers which exhibit a low ionization potential, matching with the chemical potentials of the adsorbates.

These different surface modifications of hydrogenated HPHT NDs suggest their chemical reactivity is very similar to the one of hydrogenated diamond surfaces. In the Part 4.5, surface properties of hydrogenated nanodiamonds will be discussed.

\subsubsection{Oxidation of Nanodiamonds}

The surface chemistry of pristine nanodiamonds is highly heterogeneous (Part 4.3). The selective formation of $\mathrm{C}-\mathrm{O}$ bonds at the surface by applying specific treatments is a major challenge to obtain more efficient graftings.

Among $\mathrm{C}-\mathrm{O}$ groups, carboxylic acid termination has a specific interest. Indeed, its basic form $\left(\mathrm{COO}^{-}\right)$confers a negative charge to the NDs over a wide $\mathrm{pH}$ range in water [75]. This ensures stable colloidal suspensions (Part 4.5). Surface of NDs could be saturated with carboxyl functions using nitric $\left(\mathrm{HNO}_{3}\right)$, sulfuric $\left(\mathrm{H}_{2} \mathrm{SO}_{4}\right)$ or perchloric $(\mathrm{HCl})$ acids. A mixture of these acids in equal amounts reveals powerful [45, 89, 123]. "Piranha" water (sulfuric acid and hydrogen peroxide) constitutes an efficient alternative [124]. Air annealing of NDs at $400-450{ }^{\circ} \mathrm{C}$ leads to the formation of acid functions mainly carboxylic and to the etching of non-diamond carbon [89, 125, 126]. A quantitative analysis of $\mathrm{COOH}$ groups was performed using Boehm titration after acid treatment [127]. The mean amount corresponds to $0.85 \mathrm{COOH}$ groups par $\mathrm{nm}^{2}$ of $\mathrm{ND}$ surface. Recently, ozone purification treatment was reported leading to the formation of anhydrides [46].

Starting from pristine nanodiamonds, several procedures inducing hydroxyl terminations were reported. First, chemical reduction can be performed with borane $\left(\mathrm{BH}_{3}\right)$ or hydrides $(\mathrm{LiAlH})_{4}$ starting from $\mathrm{COOH}$ [128, 129]. Second, C-OH bonds can also be formed using the "Fenton reaction" which takes place in a mixture of hydrogen peroxide and iron sulfate in strong acid solution [91, 130]. Third, a significant amount of hydroxyl groups can be generated during milling [69] or BASD [84] of NDs in water. More recently, a photochemical oxidation under UV was performed on NDs previously hydrogenated [93].

A recent review provides more details on the different oxidation procedures [28].

\subsubsection{Amination, Fluorination or Chlorination of Nanodiamonds}

Several attempts to generate fluorine, amine or chlorine terminations at NDs surface by annealing under controlled atmosphere were reported [36, 94, 131, 132]. Nevertheless, annealing temperatures are usually limited to avoid surface graphitization (Part 4.4.4). As a consequence, some oxidized groups and non-diamond carbon may remain at the surface. The selectivity of these gaseous treatments is often limited: after heating in ammonia flow, aminogroups, $\mathrm{C} \equiv \mathrm{N}$ and $\mathrm{C}=\mathrm{N}$-containing groups were identified at ND surface $[132,133]$. In order to create more reactive species, a $\mathrm{CF}_{4}$ atmospheric pressure plasma was used [95]. Chlorination of NDs was also successfully achieved by photochemical reaction of gaseous chlorine with NDs previously hydrogenated [96]. The interaction of these chlorinated NDs with ammonia led to the formation of $\mathrm{NH}_{2}$ groups.

\subsubsection{Surface Graphitization of Nanodiamonds}

Diamond graphitization can be induced by different mechanisms: via thermal treatment under vacuum [134, 135] or exposure to reactive gas under ambient atmosphere [136-138]. It can be also obtained by beam irradiation (electron, ion, laser, gamma-ray) [139-141]. Finally, the graphitization could be catalyzed by metals as Fe or Co [142-144].

A recent review was devoted to diamond phase transitions at nanoscale [145]. For nanodiamond, the graphitization process can lead to a full transformation into onion like carbon (OLC) structures formed by concentric closed graphitic shells. Corresponding kinetics were extensively studied experimentally by annealing at temperatures included between 1100 and $1900{ }^{\circ} \mathrm{C}$ in different atmospheres (vacuum, oxygen, argon, hydrogen) [100, 111, 146150]. Formations of curved graphite like structures and concentric-shells fullerenes on nanodiamonds were theoretically investigated [151-153]. For nanodiamonds 4-5 nm in size, the evolution of carbon bulk density measured by a gamma-ray attenuation method drops from 3.1 to $2.2 \mathrm{~g} \mathrm{~cm}^{-3}$ in the $900-1300{ }^{\circ} \mathrm{C}$ temperature range [154]. By comparison, the diamond/ graphite transition occurs above $1600{ }^{\circ} \mathrm{C}$ for bulk diamond [154, 155]. Starting from detonation nanodiamonds, HRTEM revealed the formation of fullerene like shells after an annealing at $1100-$ $1300{ }^{\circ} \mathrm{C}$ [146]. At $1500{ }^{\circ} \mathrm{C}$, nanodiamonds are completely converted into OLC structures while polygonal hollow onions are formed at temperatures higher than $1870{ }^{\circ} \mathrm{C}$ (Fig. 4.6). OLC have promising properties for energy storage, catalysis or composites [147-149, 156]. 
The graphitization mechanism is strongly sensitive to the presence of non-diamond carbon at the NDs surface [145]. Indeed, detonation NDs underwent purification procedures which can differ from a supplier to another (Part 4.2). This can explain the wide dispersion for the onset temperature of nanodiamonds graphitization reported in the literature, it varies from 670 to $1000{ }^{\circ} \mathrm{C}[157,158]$. The selective desorption of oxygen groups has also a significant effect on the graphitization onset. For HPHT NDs, a size effect is expected with a higher temperature suitable to initiate graphitization. Graphitization kinetics for submicron diamond and NDs were compared, different graphitization rates were determined [154].

Moreover, the previous report demonstrates that activation energies differ for $\{110\}$ and $\{111\}$ crystallographic facets $[145,159]$.

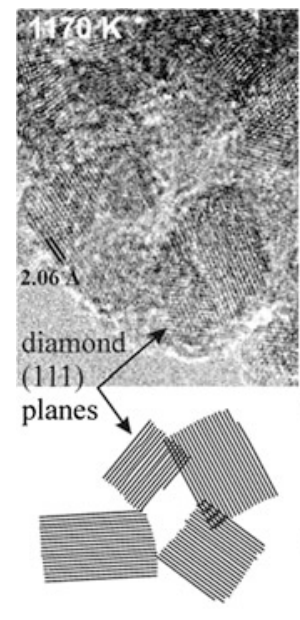

Initial Nanodiamond

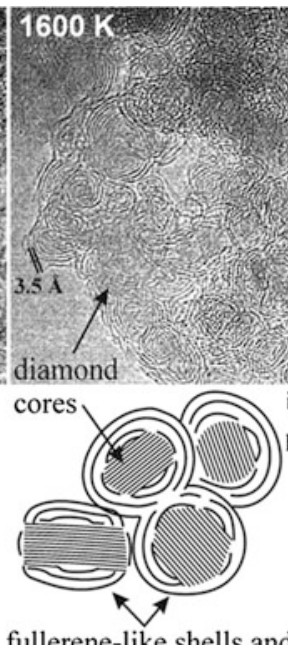

fullerene-like shells and graphite curved layers $1400-1600 \mathrm{~K}$

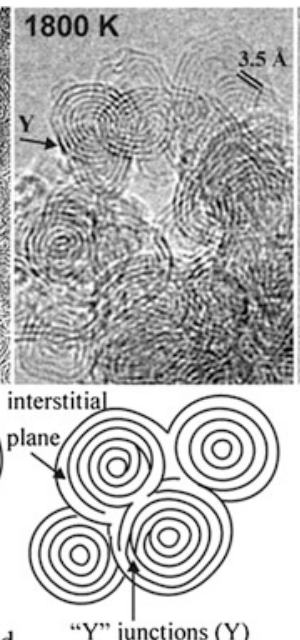

Onion-Like Carbon 1800-1900 K

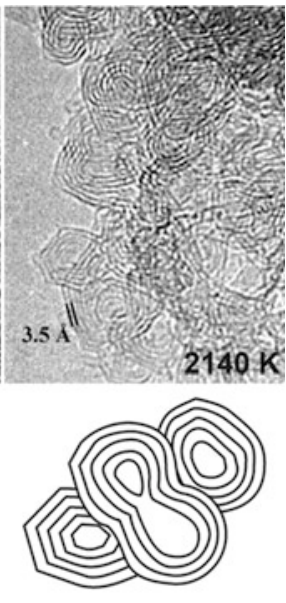

Polygonal hollow onions $>2100 \mathrm{~K}$

Fig. 4.6 Transformation of NDs into onion like carbon [146] courtesy of Y.V. Butenko, ESTEC, The Netherlands

Recently, several groups focused on the early stages of surface graphitization of detonation NDs using XPS, HRTEM, Raman or NMR characterizations [55, 75, 99, 160, 161]. The aim is to control the formation of hybrid nanoparticles with a $\mathrm{sp}^{2}$ organized surface covering a $\mathrm{sp}^{3}$ core, thus avoiding the graphitization of the diamond core. Such hybrid NPs may have promising properties linked to fullerene or graphene assets as radiosensitization or photothermal therapy [162, 163]. In addition, surface graphitized nanodiamonds exhibit electrical conductivity sufficient for electrochemical applications [164, 165].

Surface graphitization of detonation NDs by annealing under UHV was monitored using XPS [55]. The evolution of the carbon core level $(\mathrm{C} 1 \mathrm{~s})$ shows the existence of two regimes according to annealing temperature $\mathrm{T}$ (Fig. 4.7). For $\mathrm{T}$ included between 700 and $900{ }^{\circ} \mathrm{C}$, surface graphitization is initiated from non-diamond carbon present at ND surface. Fullerene like reconstructions (FLRs) are formed as shown by HRTEM [75]. On the other hand, for T $>900$ ${ }^{\circ} \mathrm{C}$, the diamond core starts to graphitize leading to the formation of bucky diamond. It is thus possible to generate FLRs at the surface without altering the diamond core. The stability of FLRs at the NDs surface was previously demonstrated by ab initio calculations confirmed by x-ray absorption and emission [152]. The selective synthesis of a thin graphitic layer on the ND surface by annealing under vacuum at temperature lower than $900{ }^{\circ} \mathrm{C}$ gives rise to hybrid nanocarbons combining the intrinsic core properties of diamond with the surface reactivity of $\mathrm{sp}^{2}$-based nanomaterials. These results were recently confirmed by a Raman study of the $\mathrm{sp}^{3}$ to $\mathrm{sp}^{2}$ conversion for detonation NDs [160]. NMR and EPR investigations detect the early stages of graphitization for annealing temperatures included between 600 and $800{ }^{\circ} \mathrm{C}$ [161].

Proper conditions determined for surface graphitization were then reported in a set-up where nanodiamonds are annealed under vacuum in a crucible. Annealed NDs are dispersable in water, their colloidal properties will be discussed in the Part 4.5. HRTEM observations confirm the structure modifications previously described showing FLRs formation [75]. A specific chemical reactivity was reported for detonation NDs after annealing at $750{ }^{\circ} \mathrm{C}$ exhibiting FLRs structures allowing arylation reactions [99].

In conclusion, surface chemistry of nanodiamonds can be tuned by thermal annealing, plasma exposure or chemical reactions. Hydrogenated and carboxylated NDs are currently well controlled whereas hydroxylation remains more difficult to achieve. These terminations are particularly suitable for the grafting of biomolecules or drugs on NDs $[28,36]$. $\mathrm{Sp}^{2}$ reconstructions can be generated at detonation NDs surface without altering the diamond core [55]. Arylation reactions allow their functionalization with complex organic moieties for bioapplications [99]. On the other hand, further progresses are needed to control the selectivity of amination, fluorination and chlorination of NDs. 
The control of NDs surface charge is essential for electrostatic loading of drugs [27, 31]. Moreover, it greatly influences the interaction with cell membrane and the internalization pathways of NDs into cells [166]. The control of surface terminations allows a tuning of NDs surface charge in suspension from negative to positive versus $\mathrm{pH}$. Colloidal properties of modified nanodiamonds in water will be now presented (Part 4.5). The link between their Zeta potential and their surface electronic properties will be investigated in details.
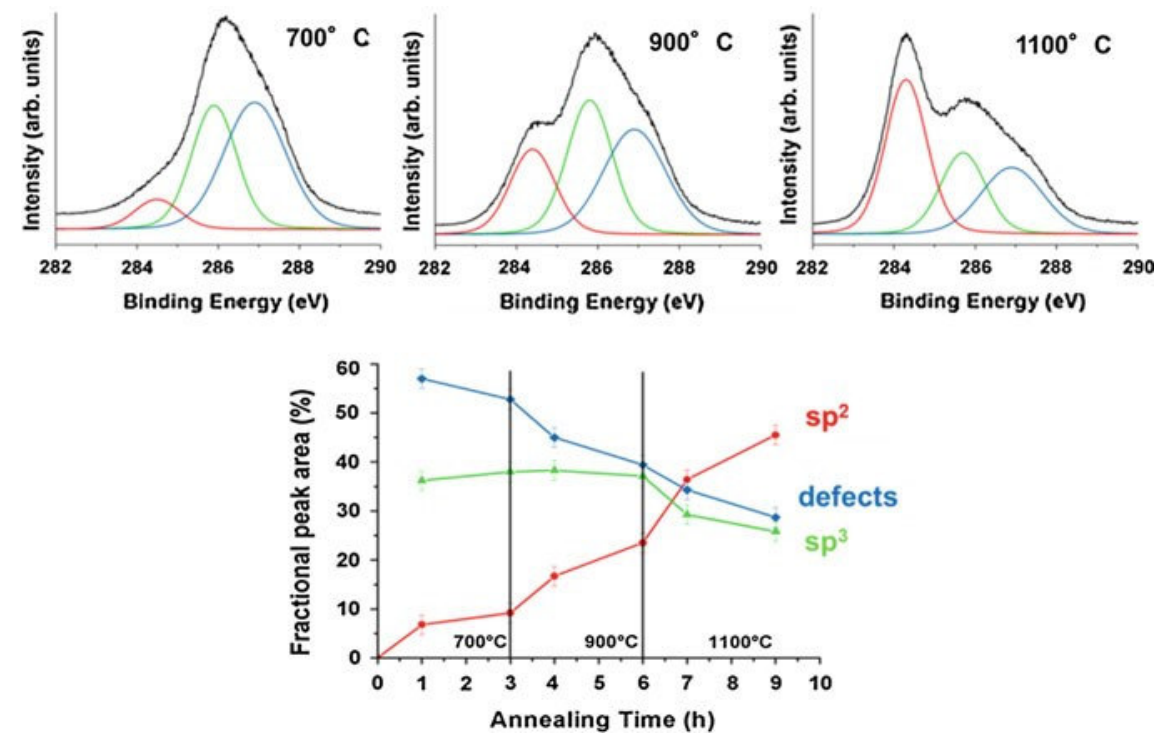

Fig. 4.7 C1s XPS spectra of NDs after sequential annealing treatments of $3 \mathrm{~h}$ at $700,900,1100{ }^{\circ} \mathrm{C}$. Fitting components CI (red), CII (green), CIII (blue), related to $\mathrm{sp}^{2}$ carbon-carbon bonds, $\mathrm{sp}^{3}$ carbon-carbon bonds, and defects, respectively, are plotted under the experimental curves. Evolution of the fractional peak areas versus annealing time [55]

\subsection{Colloidal Properties of Modified Nanodiamonds}

The colloidal stability of nanodiamonds in biologic media is of major interest for their biomedical applications. It strongly depends on their surface charge which controls hydrophilic/hydrophobic interactions with other NDs and moieties. Moreover, in the biological media, proteins adsorption leads to the formation of a corona [167] surrounding nanoparticles. The nature of proteins forming the corona is a key parameter for cell internalization pathways which occur by their specific recognition. In liquid media, nanodiamonds tend to form aggregates, this may be favored by opposite charged facets [168] or by graphitic carbon present at NDs surface $[69,128]$. Several experimental methods were developed to reduce aggregation and obtain monodisperse colloidal suspensions. Bead assisted sonic disintegration (BASD) was performed using ceramic microbeads, nevertheless, it can produce chemical contaminations or surface graphitization $[84,169,170]$. Dry milling using salts and sugars avoiding contamination was also reported [171]. Modifications in NDs surface chemistry like plasma hydrogenation [86], surface graphitization [99], oxidation in air [85] or borane reduction [128] have also proved their efficiency for deaggregation.

The behavior of nanoparticles in liquid media could be investigated by Dynamic Light Scattering (DLS). From diffused intensity signal, this technique provides the measurement of the hydrodynamic diameter of stable NPs. This diameter is higher than the real one because it includes the solvated layer of adsorbed ions which is solvent and ionic force dependent [172]. The Zeta Potential (ZP) is defined from the double layer model (Stern and Gouy-Chapman layers) which describes the counterions adsorption. ZP is the potential at the surface of the electrical double layer called slipping plane. It is obviously related to the surface charge of NDs, very different values are obtained versus surface chemistry and size [24]. Zeta Potential is calculated from the electrophoretic mobility measured in DLS. Its evolution versus $\mathrm{pH}$ must be investigated. Indeed, functional groups present at NDs surface can switch from protonated to deprotonated states according to their $\mathrm{pKa}$ value. The colloidal stability will be then dependent on $\mathrm{pH}$ value. Indeed, the ZP governs the electrostatic repulsive interactions in liquid medium. Stable NPs in colloids usually exhibit ZP potential absolute value higher than $30 \mathrm{mV}[173,174]$.

The control of ND surface charge is essential for drug or biological moieties adsorption [27, 29, 31] it can also play a major role in internalization pathways and interactions with negatively charged cell membrane [166]. In this part, the surface reactivity of modified NDs will be discussed. Especially, stable NDs in aqueous suspensions exhibiting positive or negative ZP will be considered, mechanisms such as charge transfer leading to these specific charges will be also discussed. 


\subsubsection{Surface Reactivity of Modified NDs}

The hydrophilicity of detonation nanodiamonds from the same origin was investigated versus their surface chemistry after plasma hydrogenation, air oxidation and surface graphitization [86]. Water adsorption isotherms measured by BET revealed a significantly higher hydrophilicity for $\mathrm{H}-\mathrm{NDs}$ and $\mathrm{sp}^{2}$-NDs compared to COOH-NDs. Taking into account the specific surface area and assuming a monomolecular adsorption, hydrophilic sites were estimated to 2.2 , 1.7 and 1.4 sites $/ \mathrm{nm}^{2}$ for $\mathrm{sp}^{2}$-NDs, H-NDs and COOH-NDs, respectively. These hydrophilic sites on H-NDs and $\mathrm{sp}^{2}-$ NDs are likely to facilitate the dispersion in water of otherwise hydrophobic NDs (Part 4.5.2).

This high affinity of hydrogenated and surface graphitized NDs with oxygen is supported by XPS analysis performed after air exposure. Oxygen atomic concentrations of 6.5 at $\%$ and 4.0 at $\%$ were measured for $\mathrm{sp}^{2}$-NDs and H-NDs after air exposure [86] while it was completely removed after plasma hydrogenation or annealing under vacuum (Part 4.4) $[55,70]$.

\subsubsection{Solubility, Stability in Colloids}

Stable suspensions of individual detonation NDs in water were achieved by successive sonication and centrifugation $[88,92]$. Sonication allows the breaking of Van der Waals interactions between aggregated NDs. This is an important issue for biomedical applications because detonation nanodiamonds $(<10 \mathrm{~nm})$ are expected to be easily eliminated by kidney (Part 4.6) [21]. The colloidal stability is closely related to surface charge of NDs because of electrostatic repulsive interactions. Indeed, these interactions can also promote aggregation as discussed previously. Among the literature, positive $[129,98]$ or negative $[45,88,175-177] \mathrm{ZP}$ were reported for nanodiamonds in suspension depending on their surface chemistry. These colloidal properties constitute an important asset for nanodiamonds compared to other carbon nanomaterials. Fullerenes or carbon nanotubes exhibit hydrophobic behavior and their stability in water suspension can only be obtained after their functionalization [178-180]. These colloids of NDs in water were also used to obtain homogeneous seeding of substrates for CVD growth of thin diamond films [181, 182]. Some groups used surfactants like sodium oleate [98] or oleylamine [183] to improve the colloidal stability of NDs. Nevertheless, aqueous suspensions are more suitable for bioapplications such as drug delivery.

\subsubsection{Negatively Charged NDs}

Carboxylated nanodiamonds obtained after annealing in air (Part 4.4.2) exhibit a strong negative Zeta potential included between -30 and $-50 \mathrm{mV}$ when dispersed in water for $\mathrm{pH}>5[45,75]$. The origin of this negative potential is related to the presence at the surface of carboxylate groups $\left(\mathrm{COO}^{-}\right)$the basic form of $\mathrm{COOH}$. $\mathrm{Below} \mathrm{pH}=5$, the formation of mainly carboxylic groups $(\mathrm{COOH})$ leads to a drop of Zeta potential. This threshold $\mathrm{pH}$ value is close to the $\mathrm{pKa}$ of $\mathrm{COOH} / \mathrm{COO}^{-}$couple [184].

Several studies [69, 88, 185] reported a similar behavior i.e. negative ZP for pristine NDs. This has been explained by the presence of carboxylate groups at the NDs surface formed during purification treatments (Part 4.4).

\subsubsection{Positively Charged NDs}

Other "as received" nanodiamonds from different suppliers were stabilized in water suspensions exhibiting a positive Zeta potential $(>+30 \mathrm{mV})[45,175]$. The origin of this positive ZP is not yet clearly understood. In the literature, colloidal aqueous suspensions of positively charged NDs (ZP $>30 \mathrm{mV}$ ) were also reported after different surface modifications: reduction with borane or $\mathrm{LiAlH}_{4}$ [18, 129], UV hydroxylation [93], annealing under hydrogen flow [88], plasma hydrogenation [86] or surface graphitization [75]. These charge modifications may be related to graphitic carbon surrounding NDs core or to protonation of some chemical functional groups or lastly to intrinsic properties of hydrogenated diamond surface. Different likely mechanisms have been previously proposed in the literature and will be now discussed.

\subsubsection{Presence of Graphitic Carbon at the NDs Surface}

Gibson et al. reported positive Zeta potential for detonation nanodiamonds after two oxidization treatments $\mathrm{CrO}_{2} / \mathrm{H}_{2} \mathrm{SO}_{4}$ followed by $\mathrm{NaOH} / \mathrm{H}_{2} \mathrm{O}_{2}$ [177]. Authors attributed this positive $\mathrm{ZP}$ to electrostatic interactions between pyrone groups and $\pi$-electrons from $\mathrm{sp}^{2}$-carbon present at NDs surface corresponding to protonation of pyrone structures. Theoretical investigations supported this effect leading to carbon basicity [186, 187]. 
Williams et al. obtained a positive Zeta potential for detonation NDs exposed to hydrogen flow at $500{ }^{\circ} \mathrm{C}$ then dispersed into water solution [88]. Authors claimed it originates from the interaction of OLC structures ( $\pi$ bonding) remaining at NDs surface with oxonium ions $\left(\mathrm{H}_{3} \mathrm{O}^{+}\right)$present in water suspension at acidic $\mathrm{pH}$. Their HRTEM pictures support the presence of OLC on hydrogen treated NDs. By analogy with carbon black, authors proposed an electron-donor-acceptor complex may be formed [188]. In both previous studies, a charge exchange between species from aqueous solution and $\mathrm{sp}^{2}$ carbon remaining at NDs surface is involved.

More recently, positive Zeta potential was measured at $\mathrm{pH}<8$ on detonation NDs on which FLRs were intentionally generated by annealing under vacuum before their dispersion into water (Fig. 4.8) [75]. The origin of the positive charge was linked to the formation of endoperoxide groups by cycloaddition of $\mathrm{O}_{2}$ molecules on FLRs. BET and XPS measurements well emphasize the high reactivity of $\mathrm{sp}^{2}$-NDs toward oxygen species after air exposure [86]. In situ XPS analysis after UHV annealing suggests a reversible oxidation similar to the one observed on graphene [189]. Moreover, after in situ desorption, the FTIR spectrum exhibits an intense band at $1100 \mathrm{~cm}^{-1}$ well corresponding to $\mathrm{C}-\mathrm{O}$ stretching of ether or epoxy groups [190]. This last result supports the formation of endoperoxide groups on FLRs structures. The protonation of these endoperoxides may be the explanation for oxygen hole doping [75].

\subsubsection{Chemically Induced Positive ZP}

Ozawa et al. reported on a positive Zeta potential switching after hydroxylation of carboxylated detonation NDs by a borane reduction [191]. Hydroxyl groups probed on their NDs by FTIR measurements, allowed further silanization coupling. Shenderova et al. obtained positive ZP for detonation NDs initially carboxylated after $\mathrm{LiAlH}_{4}$ reduction

[129]. Girard et al. also observed a $\mathrm{ZP}$ inversion $(+30 \mathrm{mV}$ at $\mathrm{pH}=7$ compared to $-45 \mathrm{mV}$ initially) after UV photochemical treatment of HPHT nanodiamonds [93]. Hydroxyl groups were identified from FTIR and XPS investigations. Nevertheless, any previous work provides an explanation for this positive

charge and no link between positive ZP and hydroxylation has been currently established.

Finally, positive $\mathrm{ZP}$ potential $(25 \mathrm{mV}$ for $\mathrm{pH}$ between 2 and 3) was measured for nanodiamonds grafted with ethylenediamine (EDA) [176]. According to authors, protonation of amino groups may explain the basic properties in acidic environment.
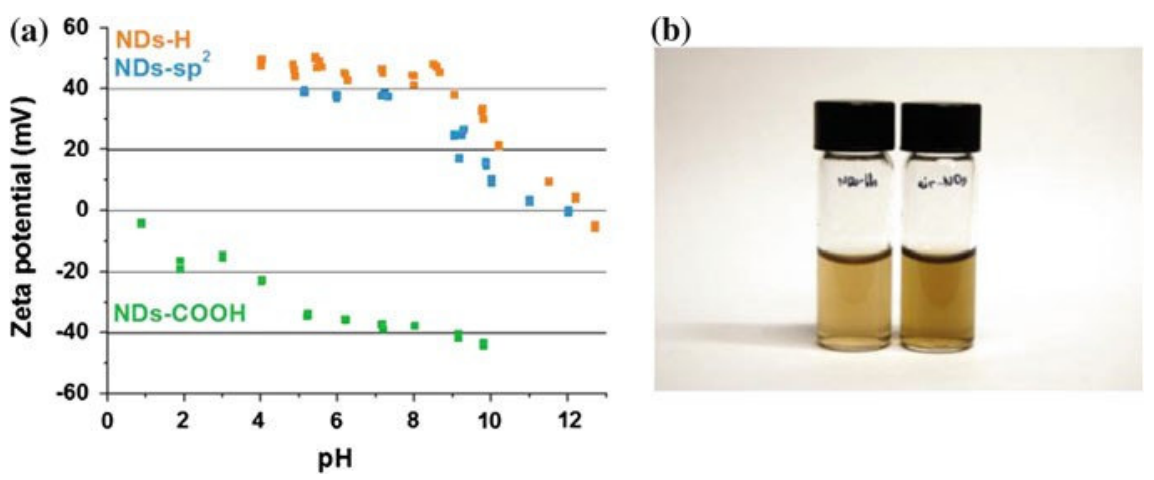

Fig. 4.8 a Zeta potential of H-NDs, COOH-NDs and $\mathrm{sp}^{2}$-NDs dispersed in water versus $\mathrm{pH}$ b Colloidal suspensions of $\mathrm{sp}^{2}$-NDs and COOH-NDs in water

\subsubsection{Specific Surface Properties of Hydrogenated Nanodiamonds}

Stable aqueous suspensions of detonation nanodiamonds previously plasma hydrogenated were recently reported [86]. Measured ZP is included between +45 and $-50 \mathrm{mV}$ for $\mathrm{pH}$ values in the range of 4-9 (Fig. 4.8). The experiment was carried out on initially negatively or positively charged NDs. According to authors, a transfer doping occurs onto $5 \mathrm{~nm}$ diamond nanoparticles suspended in water based on the semi-conductive behavior of the NDs core. These experiments show that an electrochemical exchange between residual $\mathrm{CO}_{2}$ takes place between aqueous solution and hydrogenated diamond surface leading to holes accumulation similarly to the one observed for micro-sized diamond particles [192]. The key role played by oxygen was underlined by nitrogen flushing which provokes flocculation of $\mathrm{H}-$ NDs. A transfer doping similar to the one occurring on diamond surfaces also occurs onto $5 \mathrm{~nm}$ NDs suspended in water [86]. This effect was not obvious at nanoscale. Indeed, the band bending inducing the hole accumulation layer is of the same order of magnitude than the particle diameter. This transfer doping at the hydrogenated ND surface was recently confirmed by resistivity measurements [193]. Resistivity drops from $10^{7}$ to $10^{5} \Omega \mathrm{cm}$ for detonation nanodiamonds heated in hydrogen gas $\left(600-900{ }^{\circ} \mathrm{C}\right)$. Oxidation of the hydrogenated sample at $300{ }^{\circ} \mathrm{C}$ recovers resistivity to its original value. 
To conclude, Zeta potential of nanodiamonds can be tuned over a wide $\mathrm{pH}$ range applying different surface modifications. This behaviour is highly suitable for bioapplications. According to the literature, ZP switching can be explained by charge exchanges between NDs surface and species from aqueous suspensions. Some works emphasized the role played by $\mathrm{sp}^{2}$ carbon at NDs surface. Other studies were performed using surface cleaned nanodiamonds i.e. Fenton reaction which clearly consumes a part of NDs or plasma hydrogenation. In the latter case, positive Zeta potential of H-NDs is due to specific surface properties of hydrogenated diamond surface. Neither chemical functional groups nor graphitic structures seem to be involved. This suggests mechanisms of different natures could explain thispositive surface charge.

\subsection{Nanodiamonds and Biomedical Applications}

\subsubsection{NDs Assets}

Nanodiamonds (NDs) combined many required assets for biomedical applications: extremely low cytoxicity and genotoxicity, carbon chemistry allowing covalent grafting, photoluminescent color centers, tunable size (down to 5 $\mathrm{nm})$. Let us discuss these advantages.

\subsubsection{NDs Toxicity and Biodistribution}

Several long-term in vitro [22, 194] and in vivo [195-197] previous studies demonstrated that NDs are noncytotoxic, better tolerated by cells than other nanocarbon materials [198]. NDs introduced into Caenorhabditis elegans worm did not cause any detectable stress to worms [198]. In mice, intravenous injection of $50 \mathrm{~nm}$ NDs led to long-term entrapment in the liver and the lung [195], but no mice showed any abnormal symptoms. Similarly, subcutaneous and intraperitoneal injection of $100 \mathrm{~nm}$ NDs in rats led to accumulation of NDs in retention organs over 1 month with no impact on the rats' viability [197]. However, a slight surface-dependent genotoxicity of NDs was recently reported on embryonic stem cells [199].

Until now, no extensive study combining cytotoxicity and genotoxicity of NDs was reported. A recent study [25] focuses on in vitro cytotoxicity and genotoxicity of HPHT NDs perfectly characterized in terms of size $(20 \mathrm{~nm}$ and $100 \mathrm{~nm}$ ) and surface chemistry. The cellular induced effects of two sets of NDs were investigated in six human cell lines: HepG2 and Hep3B (liver), Caki-1 and Hek-293 (kidney), HT29 (intestine) and A549 (lung). The screening of ND cytotoxicity was carried out by measuring cell impedance (xCELLigence). This technique permits real-time monitoring of NPs effects on cell morphology, proliferation, adhesion and membrane potential [200]. Flow cytometry allowed the discrimination of viable cells, containing or not NDs, and dead cells. Finally, using immunofluorescence detection of nuclear $\mathrm{Y}-\mathrm{H} 2 \mathrm{Ax}$ foci, considered the most sensitive method for detecting DNA double-strand breaks [201], genotoxicity was also analyzed. According to the results, NDs do not induce any significant toxic effect on the six cell lines up to an exposure dose of $250 \mathrm{mg} / \mathrm{mL}$ (Fig. 4.9). As a comparison, $25 \mathrm{~nm}$ $\mathrm{SiO}_{2} \mathrm{NPs}$ are 9 times more genotoxic at a 10 times lower concentration [25].
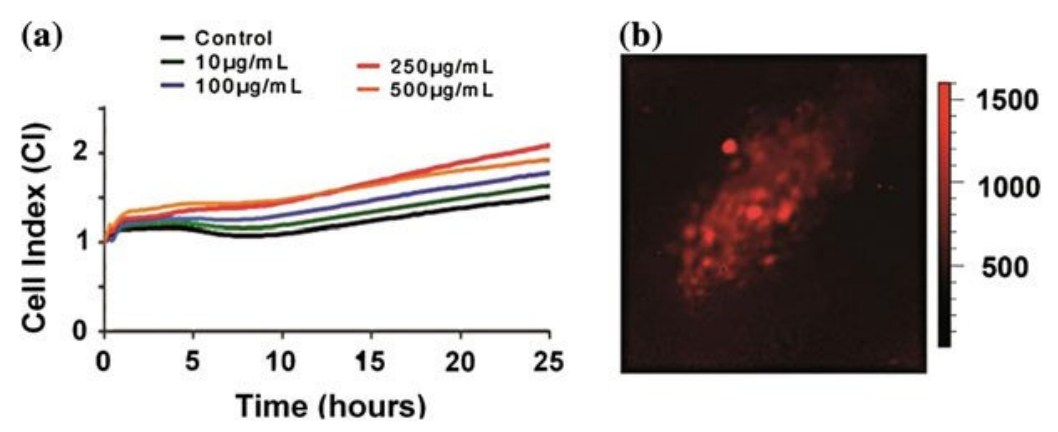

Fig. 4.9 a Cell index real-time monitoring of HepG2 cells exposed $24 \mathrm{~h}$ to $20 \mathrm{~nm}$ NDs; b Raman/ photoluminescence image on a HepG2 cell [25]

\subsubsection{Grafting of Biological Moieties}

We have previously underlined surface charge of NDs suspended in aqueous solution can be tuned over a wide $\mathrm{pH}$ range (Part 4.5) thanks to specific surface modifications (Part 4.4). Efficient surface treatments also permit to conjugate ND surfaces with fluorescent molecules [202-205], with DNA [206], siRNA [27], proteins [207, 208], lysozymes [208], growth hormones [209], antibodies [210, 211], anti-cancer drugs [30-32], as well as with dopamine derivatives [212]. 
Either covalent or non-covalent graftings were performed depending on expected bio-applications. These attempts have been recently reviewed in details [28]. The non-covalent grafting of large biomolecules based on electrostatic interactions was performed from well controlled NDs surface charge (Part 4.5). Cytochrome c [98] and bovine insulin [213] were immobilized on nanodiamonds. Furthermore, lysozymes [34, 214, 215] and apoobelin [216] were attached. Anticancer drugs like doxorubicine [217, 218], paclitaxel [30] or HCPT [32] were non-covalently adsorbed and then delivered. Some polymer coatings like polyethylenimine (PEI) have been also carried out on NDs to confer cationic surface charge for siRNA adsorption and delivery for gene therapy (Ewing's sarcoma) [27, 29, 206, 219]. In most cases, the functionality of biomolecules is preserved [214, 220] although significantly less efficiency has sometimes been observed. Cumulative effects were even obtained as lysozyme adsorption is combined with cytochrome c [215]. Depending on the functionality of the biologic unit, covalent grafting via organic chemistry could be suitable to get a specific binding site on the ND or to avoid modifications of the biomolecule conformation. Grafting routes which may involve a linker molecule could be performed from different surface terminations of NDs [28].

\subsubsection{Photoluminescent NV Centers}

Color centers could be efficiently generated in HPHT nanodiamonds by high-energy particle beam irradiation $\left(\mathrm{He}^{+}\right.$or electrons) leading to vacancy creation [124, 203]. During annealing, vacancies combined with nitrogen atoms to form NV centers which could be characterized by Photoluminescence (Part 4.3). HPHT NDs exhibited stable photoluminescence without bleaching or blinking in the red and near-infrared region corresponding to transmission window of tissues for size down to $7 \mathrm{~nm}$ [221]. These properties allowed the long-term tracking of fluorescent NDs into cells localized at subcellular scale by fluorescence and TEM microscopies. Expected applications concern biomedical imaging [203] and fluorescence energy transfer (FRET) with other fluorophores [222]. For detonation NDs, the limited nitrogen amount, the nanometric size $(<5 \mathrm{~nm})$ and structural defects present at the surface and in the diamond core prevent the observation of stable photoluminescence $[65,68]$.

\subsubsection{Tunable Size}

Nanodiamonds are scalable nanoparticles down to few nanometers [92]. For smallest NDs, in vivo clearance or kidney elimination could be expected according to the size of kidney capillarities. This constitutes an essential advantage for drug delivery or biomarkers applications. In addition, size effects on photoluminescence were reported which tune the wavelength of emitted photons [223].

\subsubsection{Some Current Challenges}

According to the previous assets, several challenges appear highly relevant and promising for the development of future bio-applications involving nanodiamonds: their labeling, their use for safer by design or their developments as a multifunctional platform for drug delivery.

\subsubsection{Labeling}

Labeling is inescapable for biodistribution and pharmacokinetics studies, for development of biomarkers or targeted drug delivery. Although NV centers are promising for in vitro imaging applications [203, 224, 225], their limited photoluminescence intensity is an obstacle to their detection in the body. In the literature, several groups reported the efficient tracking of NDs into cells by grafting of fluorophores [24, 98, 202, 226]. Bright blue luminescence was even obtained by octadecylamine covalently attached to NDs-COOH [227]. The main stake concerns the stability of fluorophores in cellular environment. An interesting alternative for tracking consists to combine NDs with contrast agents currently used for magnetic resonance imaging (MRI). The rich surface chemistry of NDs (Part 4.4) allows the covalent grafting of amine-functionalized Gd(III). Gd(III)-NDs conjugates exhibited ten times higher relaxivity and can be well detected by MRI [228]. Finally, contrary to carbon nanotubes [9], any radioactive labeling has been yet reported for nanodiamonds. This constitutes a major challenge because radioactive imaging is ordinarily used for biodistribution and pharmacokinetics studies of NPs.

\subsubsection{Safer by Design}

An important issue for drug delivery concerns the conception of safer nanoparticles [229, 230]. For this purpose, NPs physicochemical determinants such as size, shape, composition, surface chemistry or coating nature which may be critical for cytotoxic and genotoxic effects must be investigated. In vitro screening for assessing the possible reactivity, biomarkers of inflammation and cellular uptake can provide precious indications to chemists and 
physicists to design "safe" nanomaterials. According to their extremely weak in vitro toxicity [25], nanodiamonds constitute excellent candidates to study the specific effects of physical and chemical parameters on toxicity.

\subsubsection{Multifunctional Platform for Drug Delivery}

Nanodiamonds combine biocompatibility, scalability and stability in aqueous solution (Part 4.5). Moreover, several studies reported their ability to carry and deliver different classes of drugs [30-32] or nucleic acids like siRNA [26, 27, 29, 219]. To build such platform, a stable labeling is required to allow tracking of NDs. Another important issue is related to the specific targeting of proteins or DNA. A recent study

[184] reports on $20 \mathrm{~nm}$ HPHT NDs covalently grafted with peptide nucleic acids (PNA). The original functionalization route is based on an optimized amidation of ND carboxylic acids groups. ND-PNA conjugates were validated through a successful recognition of complementary DNA in a mixture, showing their efficiency toward nucleic acid detection (Fig. 4.10). Such nucleic acid functionalized NDs open the way to a wide range of biomedical applications towards genetic diseases, genomic research or early cancer diagnosis.

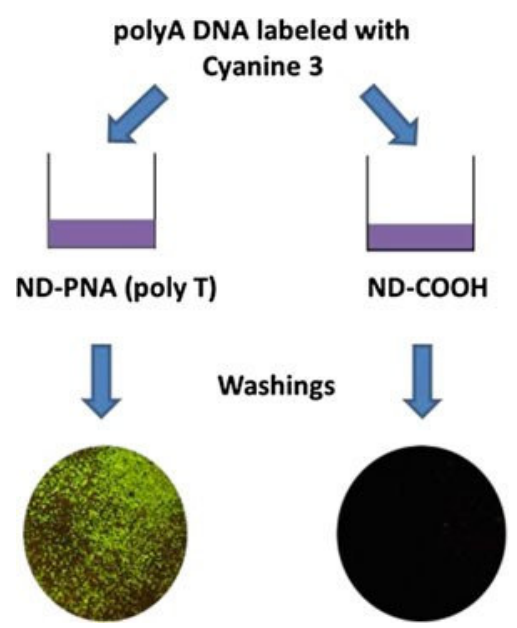

Fig. 4.10 Fluorescence of ND-PNA conjugates compared to ND-COOH after DNA hybridization observed at $\lambda_{\mathrm{exc}}=$ $550 \mathrm{~nm}$ and $\lambda_{\mathrm{em}}=570 \mathrm{~nm}[184]$

\subsection{Conclusion}

Nanodiamonds can behave very different surface properties according to their tunable surface chemistry. The current state of art of controlled surface terminations was summarized in this chapter. The link between surface chemistry, surface charge and colloidal properties of NDs was particularly emphasized. Indeed, it appears highly relevant for biomedical applications because it is a key parameter for drug adsorption or interactions with cell membrane. Among the potential surface chemistries, hydroxyl and halogen terminations $(\mathrm{F}, \mathrm{Cl}, \mathrm{Br})$ offer specific reactivity. However, experimental protocols must be further improved to reach a higher selectivity.

Some NDs characteristics related to the diamond core remain also partially understood at the present state. In particular, it is essential to further investigate the impact of structural defects or chemical impurities on NDs properties. The presence of different crystallographic facets on HPHT and some detonation NDs should also significantly influence their surface reactivity. Moreover, consequences of hydrogen incorporated in nanodiamonds especially during detonation synthesis (Part 4.2) must be better understood. According to previous works performed on bulk diamond, hydrogen should be trapped by structural defects or chemical impurities [56]. Among further main challenges for biomedecine, the radioactive labeling appears as a priority to investigate in vivo the biodistribution and pharmacokinetics on NDs. Such achievement has not been yet reported. Mechanisms of drug adsorption/desorption on NDs must be deeper understood to achieve a controlled release. These phenomena are highly sensitive to size and surface chemistry. The combination of NDs with NV centers can permit novel developments in biology like the probing of ion channels in cells or the neuron imaging. Finally, the synthesis of hybrid NDs is also an essential challenge. For example, surface graphitized NDs may possess surface properties linked to fullerene or graphene assets required for radiosensitization or photothermal therapy. In conclusion, according to their multiple assets, nanodiamonds constitute excellent candidates to be used as active NPs with therapeutic behaviors for biomedical applications. 


\section{Acknowledgments}

J.C. Arnault would like to thank H.A. Girard and T. Petit for fruitful discussions. He also acknowledges the different coworkers which contribute to studies dealing with surface modified nanodiamonds. The author also thanks Professor E. Osawa for providing detonation nanodiamonds.

\section{References}

1. M.L. Etheridge, S.A. Campbell, A.G. Erdman, C.L. Haynes, S.M. Wolf, J. McCullough, The big picture on nanomedicine: the state of investigational and approved nanomedicine products. Nanomed. Nanotechnol. Biol. Med. 9(1), 1-14 (2013). doi:10.1016/j.nano.2012.05.013

2. Y. Matsumura, H. Maeda, A new concept for macromolecular therapeutics in cancer chemotherapy: mechanism of tumoritropic accumulation of proteins and the antitumor agent smancs. Cancer Res. 46(12_Part 1), 6387$6392(1986)$

3. J.D. Byrne, T. Betancourt, L. Brannon-Peppas, Active targeting schemes for nanoparticle systems in cancer therapeutics. Adv. Drug Deliv. Rev. 60(15), 1615-1626 (2008). doi:10. 1016/j.addr.2008.08.005

4. E.V. Batrakova, A.V. Kabanov, Pluronic block copolymers: evolution of drug delivery concept from inert nanocarriers to biological response modifiers. J. Control. Release 130(2), 98-106 (2008). doi:10.1016/j.jconrel.2008.04.013

5. X. Michalet, F.F. Pinaud, L.A. Bentolila, J.M. Tsay, S. Doose, J.J. Li, G. Sundaresan, A.M. Wu, S.S. Gambhir, S. Weiss, Quantum dots for live cells, in vivo imaging, and diagnostics. Science 307(5709), 538-544 (2005). doi:10.1126/science. 1104274

6. T.A. Taton, C.A. Mirkin, R.L. Letsinger, Scanometric DNA array detection with nanoparticle probes. Science 289(5485), 1757-1760 (2000). doi:10.1126/science.289.5485.1757

7. H.B. Na, I.C. Song, T. Hyeon, Inorganic nanoparticles for MRI contrast agents. Adv. Mater. 21(21), 2133-2148 (2009). doi:10.1002/adma.200802366

8. D. Yoo, J.H. Lee, T.H. Shin, J. Cheon, Theranostic magnetic nanoparticles. Acc. Chem. Res. 44(10), 863-874 (2011). doi:10.1021/ar200085c

9. D. Georgin, B. Czarny, M. Botquin, M. Mayne-L'hermite, M. Pinault, B. Bouchet-Fabre, M. Carriere, J.L. Poncy, Q. Chau, R. Maximilien, V. Dive, F. Taran, Preparation of (14) C-labeled multiwalled carbon nanotubes for biodistribution investigations. J. Am. Chem. Soc. 131(41), 14658-14659 (2009). doi:10.1021/ja906319z

10. C.S.S.R. Kumar, F. Mohammad, Magnetic nanomaterials for hyperthermia based therapy and controlled drug delivery. Adv. Drug Deliv. Rev. 63(9), 789-808 (2011). doi:10.1016/j. addr.2011.03.008

11. K. Yang, S. Zhang, G. Zhang, X. Sun, S.T. Lee, Z. Liu, Graphene in mice: ultrahigh in vivo tumor uptake and efficient photothermal therapy. Nano Lett. 10(9), 3318-3323 (2010). doi:10.1021/nl100996u

12. K. Yang, J. Wan, S. Zhang, B. Tian, Y. Zhang, Z. Liu, The influence of surface chemistry and size of nanoscale graphene oxide on photothermal therapy of cancer using ultra-low laser power. Biomaterials 33(7), 2206-2214 (2012). doi:10.1016/j.biomaterials.2011.11.064

13. P. Cherukuri, E.S. Glazer, S.A. Curley, Targeted hyperthermia using metal nanoparticles. Adv. Drug Deliv. Rev. 62(3), 339-345 (2010). doi:10.1016/j.addr.2009.11.006

14. J.F. Hainfeld, D.N. Slatkin, H.M. Smilowitz, The use of gold nanoparticles to enhance radiotherapy in mice. Phys. Med. Biol. 49(18), N309-N315 (2004). doi:10.1088/0031-9155/ 49/18/N03

15. E. Porcel, S. Liehn, H. Remita, N. Usami, K. Kobayashi, Y. Furusawa, C. Le Sech, S. Lacombe, Platinum nanoparticles: a promising material for future cancer therapy? Nanotechnology 21(8), 85103 (2010). doi:10.1088/0957-4484/21/8/085103

16. L. Maggiorella, G. Barouch, C. Devaux, A. Pottier, E. Deutsch, J. Bourhis, E. Borghi, L. Levy, Nanoscale radiotherapy with hafnium oxide nanoparticles. Future Oncol 8(9), 1167-1181 (2012). doi:10.2217/FON.12.96

17. M.J. Sailor, J.H. Park, Hybrid nanoparticles for detection and treatment of cancer. Adv. Mater. 24(28), 37793802 (2012). doi:10.1002/adma.201200653

18. W.T. Al-Jamal, K. Kostarelos, Liposomes: from a clinically established drug delivery system to a nanoparticle platform for theranostic nanomedicine. Acc. Chem. Res. 44(10), 1094-10104 (2011). doi:10.1021/ar200105p

19. M. Liong, J. Lu, M. Kovochich, T. Xia, S.G. Ruehm, A.E. Nel, F. Tamanoi, J.I. Zink, Multifunctional inorganic nanoparticles for imaging, targeting, and drug delivery. ACS Nano 2(5), 889-896 (2008). doi:10.1021/nn800072t

20. G. Wu, A. Mikhailovsky, H.A. Khant, C. Fu, W. Chiu, J.A. Zasadzinski, Remotely triggered liposome release by near-infrared light absorption via hollow gold nanoshells. J. Am. Chem. Soc. 130(36), 8175-8177 (2008). doi:10.1021/ja802656d

21. H.S. Choi, W. Liu, P. Misra, E. Tanaka, J.P. Zimmer, B. Itty Ipe, M.G. Bawendi, J.V. Frangioni, Renal clearance of quantum dots. Nat. Biotechnol. 25(10), 1165-1170 (2007). doi:10.1038/nbt1340

22. V. Vaijayanthimala, Y.K. Tzeng, H.C. Chang, C.L. Li, The biocompatibility of fluorescent nanodiamonds and their mechanism of cellular uptake. Nanotechnology 20(42), 425103 (2009). doi:10.1088/09574484/20/42/425103 
23. Y. Yuan, X. Wang, G. Jia, J.H. Liu, T. Wang, Y. Gu, S.T. Yang, S. Zhen, H. Wang, Y. Liu, Pulmonary toxicity and translocation of nanodiamonds in mice. Diam. Relat. Mater. 19(4), 291-299 (2010). doi:10.1016/j.diamond.2009.11.022

24. A.M. Schrand, S.A.C. Hens, O.A. Shenderova, Nanodiamond particles: properties and perspectives for bioapplications. Crit. Rev. Solid State Mater. Sci. 34(1-2), 18-74 (2009). doi:10.1080/10408430902831987

25. V. Paget, J.A. Sergent, R. Grall, S. Altmeyer-Morel, H.A. Girard, T. Petit, G. Gesset, M. Mermoux, P. Bergonzo, J.C. Arnault, S. Chevillard, Carboxylated nanodiamonds are neither cytotoxic nor genotoxic on kidney, intestine, lung and liver human cell lines. Nanotoxicology. 8(S1), 46-56 (2014). doi: $10.3109 / 17435390.2013 .855828$

26. B. Zhang, Y. Li, C.Y. Fang, C.C. Chang, C.S. Chen, Y.Y. Chen, H.C. Chang, Receptor-mediated cellular uptake of folate-conjugated fluorescent nanodiamonds: a combined ensemble and single-particle study. Small 5(23), 2716-2721 (2009). doi:10.1002/smll. 200900725

27. A. Alhaddad, M.P. Adam, J. Botsoa, G. Dantelle, S. Perruchas, T. Gacoin, C. Mansuy, S. Lavielle, C. Malvy, F. Treussart, J.R. Bertrand, Nanodiamond as a vector for siRNA delivery to Ewing sarcoma cells. Small 7(21), 3087-3095 (2011). doi:10.1002/smll.201101193

28. A. Krueger, D. Lang, Functionality is key: recent progress in the surface modification of nanodiamond. Adv. Funct. Mater. 22(5), 890-906 (2012). doi:10.1002/adfm.201102670

29. A. Alhaddad, C. Durieu, G. Dantelle, E. Le Cam, C. Malvy et al., Influence of the internalization pathway on the efficacy of siRNA delivery by cationic fluorescent nanodiamonds in the Ewing sarcoma cell model. PLoS ONE 7(12), e52207 (2012). doi:10.1371/journal.pone.0052207

30. K.K. Liu, W.W. Zheng, C.C. Wang, Y.C. Chiu, C.L. Cheng, Y.S. Lo, C. Chen, J.I. Chao, Covalent linkage of nanodiamond-paclitaxel for drug delivery and cancer therapy. Nanotechnology 21(31), 315106 (2010). doi:10.1088/0957-4484/21/31/315106

31. E.K. Chow, X.Q. Zhang, M. Chen, R. Lam, E. Robinson, H. Huang, D. Schaffer, E. Osawa, A. Goga, D. Ho, Nanodiamond therapeutic delivery agents mediate enhanced chemoresistant tumor treatment. Sci. Transl. Med. 3(73), 73ra21 (2011). doi:10.1126/scitranslmed.3001713

32. J. Li, Y. Zhu, W. Li, X. Zhang, P. Peng, Q. Huang, Nanodiamonds as intracellular transporters of chemotherapeutic drug. Biomaterials 31(32), 8410-8418 (2010). doi:10.1016/ j.biomaterials.2010.07.058

33. Y.R. Chang, H.Y. Lee, K. Chen, C.C. Chang, D.S. Tsai, C.C. Fu, T.S. Lim, Y.K. Tzeng, C.Y. Fang, C.C. Han, H.C. Chang, W. Fann, Mass production and dynamic imaging of fluorescent nanodiamonds. Nat. Nanotech. 3, 284-288 (2008). doi:10.1038/nnano.2008.99

34. J.I. Chao, E. Perevedentseva, P.H. Chung, K.K. Liu, C.Y. Cheng, C.C. Chang, C.L. Cheng, Nanometer-sized diamond particle as a probe for biolabeling. Biophys. J. 93(6), 2199-2208 (2007). doi:10.1529/biophysj.107.108134

35. F.P. Bundy, W.A. Bassett, M.S. Weathers, R.J. Hemley, H.K. Mao, A.F. Goncharov, The pressure-temperature phase and transformation diagram for carbon; updated through 1994. Carbon 34(2), 141-153 (1996). doi:10.1016/0008-6223(96)00170-4

36. V.N. Mochalin, O. Shenderova, D. Ho, Y. Gogotsi, The properties and applications of nanodiamonds. Nat. Nanotech. 7, 11-23 (2012). doi:10.1038/NNANO.2011.209

37. F.P. Bundy, H.T. Hall, H.M. Strong, R.H. Wentorf, Man-made diamonds. Nature 176(4471), 51-55 (1955). doi:10.1038/176051a0

38. J.C. Angus, C.C. Hayman, Low-pressure, metastable growth of diamond and "diamondlike" phases. Science 241(4868), 913-921 (1988). doi:10.1126/science.241.4868.913

39. G.W. Yang, J.B. Wang, Q.X. Liu, Preparation of nano-crystalline diamonds using pulsed laser induced reactive quenching. J. Phys.: Condens. Matter 10(35), 7923-7928 (1998). doi:10.1088/0953-8984/10/35/024

40. J. Sun, S.L. Hu, X.W. Du, Y.W. Lei, Ultrafine diamond synthesized by long-pulse-width laser. Appl. Phys. Lett. 89(18), 183115 (2006). doi:10.1063/1.2385210

41. J.P. Boudou, P.A. Curmi, F. Jelezko, J. Wrachtrup, P. Aubert, M. Sennour, G. Balasubramanian, R. Reuter, A. Thorel, E. Gaffet, High yield fabrication of fluorescent Nanodiamonds. Nanotechnology 20(35), 235602 (2009). doi:10.1088/0957-4484/20/35/359801

42. J.P. Boudou, J. Tisler, R. Reuter, A. Thorel, P.A. Curmi, F. Jelezko, J. Wrachtrup, Fluorescent nanodiamonds derived from HPHT with a size of less than $10 \mathrm{~nm}$. Diam. Relat. Mater. 37, 80-86 (2013). doi:10.1016/j.diamond.2013.05.006

43. E. Neu, C. Arend, E. Gross, F. Guldner, C. Hepp, D. Steinmetz, E. Zscherpel, S. Ghodbane, H. Sternschulte, D. Steinmüller-Nethl, Y. Liang, A. Krueger, C. Becher, Narrowband fluorescent nanodiamonds produced from chemical vapor deposition films. Appl. Phys. Lett. 98(24), 243107 (2011). doi:10.1063/1.3599608

44. V. Danilenko, O. Shenderova, Advances in synthesis of nanodiamond particles. In Ultrananocrystalline Diamond: Synthesis, Properties and Applications, 2nd edn. ed. By O. Shenderova, D.M. Gruen (Elsevier, 2012)

45. V.Y. Dolmatov, Detonation-synthesis nanodiamonds: synthesis, structure, properties and applications. Russ. Chem. Rev. 76(4), 339-360 (2007). doi:10.1070/RC2007v076n04 ABEH003643

46. O. Shenderova, A. Koscheev, N. Zaripov, I. Petrov, Y. Skryabin, P. Detkov, T. Turner, G. Van Tendeloo, Surface chemistry and properties of ozone-purified detonation nanodiamonds. J. Phys. Chem. C 115(20), 9827- 
9837 (2011). doi:10.1021/jp1102466

47. J.E. Dahl, S.G. Liu, R.M.K. Carlson, Isolation and structure of higher diamondoids, nanometer-sized diamond molecules. Science 299(5603), 96-102 (2003). doi:10.1126/ science.1078239

48. O.O. Mykhaylyk, Y.M. Solonin, D.N. Batchelder, R. Brydson, Transformation of nanodiamond into carbon onions: a comparative study by high-resolution transmission electron microscopy, electron energy-loss spectroscopy, x-ray diffraction, small-angle x-ray scattering, and ultraviolet Raman spectroscopy. J. Appl. Phys. 97(7), 074302 (2005). doi:10. 1063/1.1868054

49. E. Osawa, D. Ho, Nanodiamond and its application to drug delivery. J. Med. Allied Sci. 2(2), 31-40 (2012)

50. A.S. Barnard, M. Sternberg, Crystallinity and surface electrostatics of diamond nanocrystals. J. Mater. Chem. 17(45), 4811-4819 (2007). doi:10.1039/b710189aS. Turner, O.I. Lebedev, O. Shenderova, I.I. Vlasov, J. Verbeeck, G. Van Tendeloo, Determination of size, morphology, and nitrogen impurity location in treated detonation nanodiamond by transmission electron microscopy. Adv. Funct. Mater. 19(13), 2116-2124 (2009). doi:10.1002/adfm.200801872

51. D.C. Bell, C.J. Russo, D.V. Kolmykov, $40 \mathrm{keV}$ atomic resolution TEM. Ultramicroscopy 114, 38-45 (2012). doi:10.1016/j.ultramic.2011.12.001

52. B. Palosz, S. Stelmakh, E. Grzanka, S. Gierlotka, W. Palosz, Application of apparent lattice parameter to determination of core-shell structure of nanocrystals. Z. Kristallogr. 222(11), 580-594 (2007). doi:10.1524/zkri.2007.222.11.580

53. V.L. Kuznetsov, M.N. Aleksandrov, I.V. Zagoruiko, A.L. Chuvilin, E.M. Moroz, V.N. Kolomiichuk, V.A. Lizholobov, P.M. Brylyakov, G.V. Sakovitch, Study of ultradispersed diamond powders obtained using explosion energy. Carbon 29(4-5), 665-668 (1991). doi:10. 1016/0008-6223(91)90135-6

54. T. Petit, J.C. Arnault, H.A. Girard, M. Sennour, P. Bergonzo, Early stages of surface graphitization on nanodiamond probed by x-ray photoelectron spectroscopy. Phys. Rev. B 84 (23), 233407 (2011). doi:10.1103/PhysRevB.84.233407

55. D. Ballutaud, F. Jomard, T. Kociniewski, E. Rzepka, H.A. Girard, S. Saada, Sp(3)/sp(2) character of the carbon and hydrogen configuration in micro- and nanocrystalline diamond. Diam. Relat. Mater. 17(4-5), 451-456 (2008). doi:10.1016/j.diamond.2007.10.004

56. B.R. Smith, D. Inglis, B. Sandnes, J. Rabeau, A.V. Zvyagin, D. Gruber, C.J. Noble, R. Vogel, E. Osawa, T. Plakhotnik, Five-nanometer diamond with luminescent nitrogen-vacancy defect centers. Small 5(14), 16491653 (2009). doi:10.1002/smll.200801802

57. V. Fionov, A. Lund, W.M. Chen, N.N. Rozhkova, I.A. Buyanova, G.I. Emel'yanova, L.E. Gorlenko, E.V. Golubina, E.S. Lokteva, E. Osawa, V.V. Lunin, Paramagnetic centers in detonation nanodiamonds studied by CW and pulse EPR. Chem. Phys. Lett. 493(4-6), 319-322 (2010). doi:10.1016/j.cplett.2010.05.050

58. J.H.N. Loubser, J.A. Van Wyk, Electron spin resonance in the study of diamond. Rep. Progr. Phys. 41(8), 12011248 (1978). doi:10.1088/0034-4885/41/8/002

59. V. Pichot, O. Stephan, M. Comet, E. Fousson, J. Mory, K. March, D. Spitzer, High nitrogen doping of detonation nanodiamonds. J. Phys. Chem. C 114(22), 10082-10087 (2010). doi:10.1021/jp9121485

60. Y.G. Lu, S. Turner, J. Verbeeck, S.D. Janssens, P. Wagner, K. Haenen, G. Van Tendeloo, Direct visualization of boron dopant distribution and coordination in individual chemical vapor deposition nanocrystalline B-doped diamond grains. Appl. Phys. Lett. 101(4), 041907 (2012). doi:10.1063/1.4738885

61. S. Turner, Y.G. Lu, S.D. Janssens, F. Da Pieve, D. Lamoen, J. Verbeeck, K. Haenen, P. Wagner, G. Van Tendeloo, Local boron environment in B-doped nanocrystalline diamond films. Nanoscale 4(19), 5960-5964 (2012). doi:10.1039/c2nr31530k

62. A.V. Kvit, V.V. Zhirnov, T. Tyler, J.J. Hren, Aging effect and nitrogen distribution in diamond nanoparticles. Comp. Part B Eng. 35(2), 163-166 (2004). doi:10.1016/j. compositesb.2003.08.003

63. I.I. Vlasov, Hydrid diamond-graphite nanowires produced by microwave plasma chemical vapor deposition. Adv. Mater. 19(22), 4058-4062 (2007). doi:10.1002/adma.200700442

64. O.A. Shenderova, I.I. Vlasov, S. Turner, G. Van Tendeloo, S.B. Orlinskii, A.A. Shiryaev, A.A. Khomich, S.N. Sulyanov, F. Jelezko, J. Wrachtrup, Nitrogen control in nanodiamond produced by detonation shock-waveassisted synthesis. J. Phys. Chem. C 115(29), 14014-14024 (2011). doi:10.1021/jp202057q 65. T. Berg, E. Marosits, J. Maul, P. Nagel, U. Ott, F. Schertz, S. Schuppler, C. Sudek, G. Schonhense, Quantum confinement observed in the X-ray absorption spectrum of size distributed meteoritic nanodiamonds. J. Appl. Phys. 104(6), 064303 (2008). doi:10.1063/1. 2978217

66. A.M. Panich, Nuclear magnetic resonance studies of nanodiamonds. Crit. Rev. Solid State Mater. Sci. 37(4), 276-303 (2012). doi:10.1080/10408436.2011.606930C. Bradac, T. Gaebel, N. Naidoo, M.J. Sellars, J. Twamley, L.J. Brown, A.S. Barnard, T. Plakhotnik, A.V. Zvyagin, J.R. Rabeau, Observation and control of blinking nitrogen-vacancy centres in discrete nanodiamonds. Nat. Nanotech. 5, 345-349 (2010). doi:10.1038/ NNANO.2010.56

67. A. Krüger, F. Kataoka, M. Ozawa, T. Fujino, Y. Suzuki, A.E. Aleksenskii, A. Ya, A. Vul, E. Osawa, Unusually tight aggregation in detonation nanodiamond: identification and disintegration. Carbon 43(8), 17221730 (2005). doi:10.1016/j.carbon.2005.02.020

68. J.C. Arnault, T. Petit, H.A. Girard, A. Chavanne, C. Gesset, M. Sennour, M. Chaigneau, Surface chemical modifications and surface reactivity of nanodiamonds hydrogenated by CVD plasma. Phys. Chem. Chem. Phys. 
13(6), 11481 (2011). doi:10.1039/c1cp20109c

69. M. Mermoux, B. Marcus, G.M. Swain, J.E. Butler, A confocal raman imaging study of an optically transparent boron-doped diamond electrode. J. Phys. Chem. B 106(42), 10816-10827 (2002). doi:10.1021/jp0202946

70. S. Osswald, V.N. Mochalin, M. Havel, G. Yushin, Y. Gogotsi, Phonon confinement effects in the Raman spectrum of nanodiamond. Phys. Rev. B 80(7), 075419 (2009). doi:10.1103/ PhysRevB.80.075419

71. M. Chaigneau, G. Piccardi, H.A. Girard, J.C. Arnault, R. Ossikovski, Laser heating versus phonon confinement effect in the Raman spectra of diamond nanoparticles. J. Nanopart. Res. 14(6), 955 (2012). doi:10.1007/s11051012-0955-9

72. D.R. Baer, M.H. Engelhard, XPS analysis of nanostructured materials and biological surfaces. J. Electron Spectrosc. Relat. Phenom. 178-179, 415-432 (2010). doi:10.1016/j. elspec.2009.09.003

73. T. Petit, J.C. Arnault, H.A. Girard, M. Sennour, T.Y. Kang, C.L. Cheng, P. Bergonzo, Oxygen hole doping of nanodiamond. Nanoscale 4(21), 6792 (2012). doi:10.1039/ c2nr31655b

74. S. Michaelson, A. Stacey, R. Akhvlediani, S. Prawer, A. Hoffman, High resolution electron energy loss spectroscopy surface studies of hydrogenated detonation nano-diamond spray-deposited films. Surf. Sci. 604(15-16), 1326-1330 (2010). doi:10.1016/j.susc.2010.04.022

75. C.L. Cheng, C.F. Chen, W.C. Shaio, D.S. Tsai, K.H. Chen, The CH stretching features on diamonds of different origins. Diam. Relat. Mater. 14(9), 1455-1462 (2005). doi:10.1016/j. diamond.2005.03.003

76. P.H. Chung, E. Perevedentseva, J.S. Tu, C.C. Chang, C.L. Cheng, Spectroscopic study of bio-functionalized nanodiamonds. Diam. Relat. Mater. 15(4-8), 622-625 (2006). doi:10. 1016/j.diamond.2005.11.019

77. Z. Remes, H. Kozak, B. Rezek, E. Ukraintsev, O. Babchenko, A. Kromka, H.A. Girard, J.C. Arnault, P. Bergonzo, Diamond-coated ATR prism for infrared absorption spectroscopy of surface-modified diamond nanoparticles. Appl. Surf. Sci. 270, 411-417 (2013). doi:10.1016/ j.apsusc.2013.01.039

78. S. Ghodbane, A. Deneuville, D. Tromson, P. Bergonzo, E. Bustarret, D. Ballutaud, Sensitivity of Raman spectra excited at $325 \mathrm{~nm}$ to surface treatments of undoped polycrystalline diamond films. Phys. Stat. Sol. A 203(10), 2397-2402 (2006). doi:10. 1002/pssa.200521462

79. A. Crisci, M. Mermoux, B. Saubat-Marcus, Deep ultra-violet Raman imaging of CVD boron-doped and nondoped diamond films. Diam. Relat. Mater. 17(7-10), 1207-1211 (2008). doi:10.1016/j.diamond.2008.01.025

80. F. Cataldo, A. Koscheev, A study of the action of ozone and on the thermal stability of nanodiamond. Fuller. Nanotub. Carbon Nanostruct. 11(3), 201 (2003). doi:10.1081/FST-120024039

81. A. Koshcheev, Thermodesorption mass spectrometry in the light of solution of the problem of certification and unification of the surface properties of detonation nano-diamonds. Russ. J. Gener. Chem. 79(9), 2033-2044 (2009). doi:10.1134/S1070363209090357

82. A. Krueger, M. Ozawa, G. Jarre, Y. Liang, J. Stegk, L. Lu, Deagglomeration and functionalisation of detonation diamond. Physica Status Solidi A 204(9), 2881-2887 (2007). doi:10.1002/pssa.200776330

83. A.E. Aleksenskiy, E.D. Eydelman, A.Y. Vul, Deagglomeration of detonation nanodiamonds. Nanosci. Nanotechnol. Lett. 3(1), 68-74 (2011). doi:10.1166/nnl.2011.1122

84. T. Petit, H.A. Girard, A. Trouve, I. Batonneau-Genner, P. Bergonzo, J.C. Arnault, Surface transfer doping can mediate both colloidal stability and self-assembly of nanodiamonds. Nanoscale 5(19), 8958-8962 (2013). doi:10.1039/c3nr02492j

85. H.A. Girard, J.C. Arnault, S. Perruchas, S. Saada, T. Gacoin, J.P. Boilot, P. Bergonzo, Hydrogenation of nanodiamonds using MPCVD: a new route toward organic functionalization. Diam. Relat. Mater. 19(7-9), 11171123 (2010). doi:10.1016/j.diamond.2010.03.019

86. O.A. Williams, J. Hees, C. Dieker, W. Jäger, L. Kirste, C.E. Nebel, Size-dependent reactivity of diamond nanoparticles. ACS Nano 4(8), 4824-4830 (2010). doi:10.1021/nn100748k

87. S. Osswald, G. Yushin, V. Mochalin, S.O. Kucheyev, Y. Gogotsi, Control of $\mathrm{sp}^{2} / \mathrm{sp}^{3}$ carbon ratio and surface chemistry of nanodiamond powders by selective oxidation in air. J. Am. Chem. Soc. 128(36), 11635-11642 (2006). doi:10.1021/ja063303n

88. A. Krüger, Y. Liang, G. Jarre, J. Stegk, Surface functionalisation of detonation diamond suitable for biological applications. J. Mater. Chem. 16(24), 2322-2328 (2006). doi:10.1039/ b601325b

89. R. Martín, M. Álvaro, J.R. Herance, H. García, Fenton-treated functionalized diamond nanoparticles as gene delivery system. ACS Nano 4(1), 65-74 (2010). doi:10.1021/nn901616c

90. Y. Morita, T. Takimoto, H. Yamanaka, K. Kumekawa, S. Morino, S. Aonuma, T. Kimura, N. Komatsu, A facile and scalable process for size-controllable separation of nanodiamond particles as small as $4 \mathrm{~nm}$. Small 4(12), 2154-2157 (2008). doi:10.1002/smll.200800944

91. H.A. Girard, T. Petit, S. Perruchas, J.C. Arnault, P. Bergonzo, Surface properties of hydrogenated nanodiamonds: a chemical investigation. Phys. Chem. Chem. Phys. 13(32), 11511-11516 (2011). doi:10.1039/c1cp20424f

92. Y. Liu, Z. Gu, J.L. Margrave, V.N. Khabashesku, Functionalization of nanoscale diamond powder: fluoro-, alkyl-, amino-, and amino acid-nanodiamond derivatives. Chem. Mater. 16 (20), 3924-3930 (2004). doi:10.1021/cm048875q

93. M.A. Ray, T. Tyler, B. Hook, A. Martin, G. Cunningham, O. Shenderova, J.L. Davidson, M. Howell, W.P. Kang, G. McGuire, Cool plasma functionalization of nano-crystalline diamond films. Diam. Relat. Mater. 16(12), 2087-2089 (2007). doi:10.1016/j.diamond.2007. 07.016 
94. K.I. Sotowa, T. Amamoto, A. Sobana, K. Kusakabe, T. Imato, Effect of treatment temperature on the amination of chlorinated diamond. Diam. Relat. Mater. 13(1), 145-150 (2004). doi:10.1016/j.diamond.2003.10.029

95. W.S. Yeap, S. Chen, K.P. Loh, Detonation nanodiamond: an organic platform for the Suzuki coupling of organic molecules. Langmuir 25(1), 185-191 (2009). doi:10.1021/la8029787

96. C.L. Huang, H.C. Chang, Adsorption and immobilization of cytochrome c on nanodiamonds. Langmuir 20(14), 5879-5884 (2004). doi:10.1021/la0495736

97. Y. Liang, T. Meinhardt, G. Jarre, M. Ozawa, P. Vrdoljak, A. Schöll, F. Reinert, A. Krueger, Deagglomeration and surface modification of thermally annealed nanoscale diamond. J. Colloid Interface Sci. 354(1), 23-30 (2011). doi:10.1016/j.jcis.2010.10.044

98. J. Chen, S.Z. Deng, J. Chen, Z.X. Yu, N.S. Xu, Graphitization of nanodiamond powder annealed in argon ambient. Appl. Phys. Lett. 74(24), 3651 (1999). doi:10.1063/1.123211

99. Y. Liang, M. Ozawa, A. Krueger, A general procedure to functionalize agglomerating nanoparticles demonstrated on nanodiamond. ACS Nano 3(8), 2288-2296 (2009). doi:10. 1021/nn900339s

100. J.B. Cui, J. Ristein, L. Ley, Electron affinity of the bare and hydrogen covered single crystal diamond (111) surface. Phys. Rev. Lett. 81(2), 429-432 (1998). doi:10.1103/PhysRevLett. 81.429

101. L. Ley, J. Ristein, F. Meier, M. Riedel, P. Strobel, Surface conductivity of the diamond: a novel transfer doping mechanism. Phys. B 376-377, 262-267 (2006). doi:10.1016/j.physb. 2005.12.068

102. B.V. Spitsyn, S.A. Denisov, N.A. Skorik, A.G. Chopurova, S.A. Parkaeva, L.D. Belyakova, O.G. Larionov, The physical-chemical study of detonation nanodiamond application in adsorption and chromatography. Diam. Relat. Mater. 19(2-3), 123-127 (2010).doi:10.1016/ j.diamond.2009.10.020

103. S. Ida, T. Tsubota, O. Hirabayashi, M. Nagata, Y. Matsumoto, A. Fujishima, Chemical reaction of hydrogenated diamond surface with peroxide radical initiators. Diam. Relat. Mater. 12(3-7), 601-605 (2003). doi:10.1016/S0925-9635(02)00334-5

104. I.I. Obraztsova, N.K. Eremenko, Physicochemical modification of nanodiamonds. Russ. J. Appl. Chem. 81(4), 603-608 (2008). doi:10.1134/S107042720804006X

105. M.B. Smith, J. March, March's Advanced Organic Chemistry, 6th edn. (Wiley, Hoboken, 2007)

106. D. Ager, Hydrogenation of carbon-carbon double bonds, in Science of Synthesis, Stereoselective Synthesis, 1st edn. ed. by J.G. De Vries, G.A. Molander, P.A. Evans (2011), pp. 185-256

107. M. Yeganeh, P. Coxon, A. Brieva, V. Dhanak, L. Šiller, Y. Butenko, Atomic hydrogen treatment of nanodiamond powder studied with photoemission spectroscopy. Phys. Rev. B 75(15), 1-8 (2007). doi:10.1103/PhysRevB.75.155404

108. J. Angus, H.A. Will, W.S. Stanko, Growth of diamond seed crystals by vapor deposition. J. Appl. Phys. 39(6), 2915-2922 (1968). doi:10.1063/1.1656693

109. E. Van Hove, J. De Sanoit, J.C. Arnault, S. Saada, C. Mer, P. Mailley, P. Bergonzo, M. Nesladek, Stability of H-terminated BDD electrodes: an insight into the influence of the surface preparation. Phys. Stat. Solid. A 204(9), 2931-2939 (2007). doi:10.1002/pssa. 200776340

110. R. Kiran, E. Scorsone, J. De Sanoit, J.C. Arnault, P. Mailley, P. Bergonzo, Boron doped diamond electrodes for direct measurement in biological fluids: an in situ regeneration approach. J. Electrochem. Soc. 160(1), H67H73 (2013). doi:10.1149/2.014302jes

111. W.S. Yang, O. Auciello, J.E. Butler, W. Cai, J.A. Carlisle, J. Gerbi, D.M. Gruen, T. Knickerbocker, T.L. Lasseter, J.N. Russell, L.M. Smith, R.J. Hamers, DNA-modified nanocrystalline diamond thin-films as stable, biologically active substrates. Nat. Mater. 1, 253-257 (2002). doi:10.1038/nmat779

112. T. Strother, T. Knickerbocker, J. Russell, J. Butler, L. Smith, R. Hamers, Photochemical functionalization of diamond films. Langmuir 18(4), 968-971 (2002). doi:10.1021/ la0112561

113. A. Hartl, E. Schmich, J.A. Garrido, J. Hernando, S.C.R. Catharino, S. Walter, P. Feulner, A. Kromka, D. Steinmuller, M. Stutzmann, Protein-modified nanocrystalline diamond thin films for biosensor applications. Nat. Mater. 3, 736-742 (2004). doi:10.1038/nmat1204

114. Y. Zhong, K. Loh, The chemistry of C-H bond activation on diamond. Chem. Asian J. 5(7), 1532-1540 (2010). doi:10.1002/asia.201000027

115. S. Szunerits, R. Boukherroub, Different strategies for functionalization of diamond surfaces. J. Solid State Electrochem. 12(10), 1205-1218 (2008). doi:10.1007/s10008-007-0473-3

116. F. Maier, M. Riedel, B. Mantel, J. Ristein, L. Ley, Origin of surface conductivity in diamond. Phys. Rev. Lett. 85(16), 3472-3475 (2000). doi:10.1103/PhysRevLett.85.3472

117. C. Bandis, B.B. Pate, Electron-emission due to exciton breakup from negative electron-affinity diamond. Phys. Rev. Lett. 74(5), 777-780 (1995). doi:10.1103/PhysRevLett.74.777

118. B.M. Nichols, J.E. Butler, J.N. Russell, R.J. Hamers, Photochemical functionalization of hydrogen-terminated diamond surfaces: a structural and mechanistic study. J. Phys. Chem. B 109(44), 20938-20947 (2005). doi:10.1021/jp0545389

119. D. Shin, B. Rezek, N. Tokuda, D. Takeuchi, H. Watanabe, T. Nakamura, T. Yamamoto, C.E. Nebel, Photo- and electrochemical bonding of DNA to single crystalline CVD diamond. Phys. Status Solidi A 203(13), 32453272 (2006). doi:10.1002/pssa.200671402

120. S. Lud, M. Steenackers, R. Jordan, P. Bruno, D. Gruen, P. Feulner, J. Garrido, M. Stutzmann, Chemical grafting 
of biphenyl self-assembled monolayers on ultrananocrystalline diamond. J. Am. Chem. Soc. 128(51), 1688416891 (2006). doi:10.1021/ja0657049

121. Y.V. Butenko, V.L. Kuznetsov, E.A. Paukshtis, A.I. Stadnichenko, I.N. Mazov, S.I. Moseenkov, A.I. Boronin, S.V. Kosheev, The thermal stability of nanodiamond surface groups and onset of nanodiamond graphitization. Fullerenes, Nanotubes, Carbon Nanostruct. 14(2-3), 557-564 (2006). doi:10.1080/15363830600666779

122. L. Rondin, G. Dantelle, A. Slablab, F. Grosshans, F. Treussart, P. Bergonzo, S. Perruchas, T. Gacoin, M. Chaigneau, H.C. Chang, V. Jacques, J.F. Roch, Surface-induced charge state conversion of nitrogen-vacancy defects in nanodiamonds. Phys. Rev. B 82(11), 115449 (2010). doi:10.1103/PhysRevB.82.115449

123. O. Shenderova, I. Petrov, J. Walsh, V. Grichko, T. Tyler, G. Cunningham, Modification of detonation nanodiamonds by heat treatment in air. Diam. Relat. Mater. 15(11-12), 1799-1803 (2006). doi:10.1016/j.diamond.2006.08.032

124. D. Mitev, R. Dimitrova, M. Spassova, C. Minchev, S. Stavrev, Surface peculiarities of detonation nanodiamonds in dependence of fabrication and purification methods. Diam. Relat. Mater. 16(4-7), 776-780 (2007). doi:10.1016/j.diamond.2007.01.005

125. M. Comet, V. Pichot, B. Siegert, F. Britz, D. Spitzer, Detonation nanodiamonds for Doping Kevlar. J Nanosci. Nanotechnol. 10(7), 4286-4292 (2010). doi:10.1166/jnn.2010.2186

126. A. Krueger, The structure and reactivity of nanoscale diamond. J. Mater. Chem. 18(13), 1485-1492 (2008). doi: $10.1039 / \mathrm{b} 716673 \mathrm{~g}$

127. O. Shenderova, A.M. Panich, S. Moseenkov, S.C. Hens, V. Kuznetsov, H.M. Vieth, Hydroxylated detonation nanodiamond: FTIR, XPS, and NMR studies. J. Phys. Chem. C 115 (39), 19005-19011 (2011). doi:10.1021/jp205389m

128. R. Martin, P.C. Heydorn, M. Alvaro, H. Garcia, General strategy for high-density covalent functionalization of diamond nanoparticles using Fenton chemistry. Chem. Mater. 21(19), 4505-4514 (2009). doi:10.1021/cm9012602

129. G. Lisichkin, V. Korol'kov, B. Tarasevic, I. Kulakova, A. Karpukhin, Photochemical chlorination of nanodiamond and interaction of its modified surface with C-nucleophiles. Russ. Chem. Bull. 55(12), 2212-2219 (2006). doi:10.1007/s11172-006-0574-7

130. B.V. Spitsyn, J.L. Davidson, M.N. Graboboev, T.B. Galushko, N.V. Serebryakova, T.A. Karpukhina, I.I. Kulakova, N.N. Melnik, In road to modifications of detonation nanodiamond. Diam. Relat. Mater. 15(2-3), 296299 (2006). doi:10.1016/j.diamond.2005. 07.033

131. V.N. Mochalin, S. Osswald, C. Portet, G. Yushin, C. Hobson, M. Havel, Y. Gogotsi, High temperature functionalization and surface modification of nanodiamond powders. MRS Proc. 1039, 201-211 (2007). doi:10.1557/PROC-1039-P11-03

132. V. Ralchenko, L. Nistor, E. Pleuler, A. Khomich, I. Vlasov, R. Khmelnitskii, Structure and properties of hightemperature annealed CVD diamond. Diam. Relat. Mater. 12(10-11), 1964-1970 (2003). doi:10.1016/S09259635(03)00214-0

133. S. Ogawa, T. Yamada, S. Ishizduka, A. Yoshigoe, M. Hasegawa, Y. Teraoka, Y. Takakuwa, Vacuum annealing formation of graphene on diamond $\mathrm{C}(111)$ surfaces studied by real-time photoelectron spectroscopy. Jpn. J. Appl. Phys. 51(11s), 11PF02 (2012). doi:10.1143/JJAP. 51.11PF02

134. T. Evans, Changes produced by high temperature treatment of diamond, in The Properties of Natural and Synthetic Diamonds, ed. by J.E. Field (Academic Press, London, 1979), pp. 403-425

135. K.S. Uspenskaya, Y.N. Tolmachev, D.V. Fedoseev, Oxidation and graphitization of diamond at low pressures. Zh. Fiz. Khim. 56, 495 (1982) (in Russian)

136. D.V. Fedoseev, S.P. Vnusov, V.L. Bukhovets, B.A. Anikin, Surface graphitization of diamond at high temperatures. Surf. Coat. Technol. 28(2), 207-214 (1986). doi:10.1016/ 0257-8972(86)90059-9

137. G. Davies, Properties and Gowth of Diamond (INSPEC, London, 1994)

138. J.F. Prins, Ion implantation of diamond for electronics applications. Semicond. Sci. Technol. 18(3), S27 (2003). doi: $10.1088 / 0268-1242 / 18 / 3 / 304$

139. F. Banhart, Irradiation effects in carbon nanostructures. Rep. Prog. Phys. 62(8), 1181 (1999). doi:10.1088/00344885/62/8/201

140. J.E. Field (ed.), The Properties of Natural and Synthetic Diamonds (Academic Press, London, 1977)

141. O.P. Krivoruchko, V.I. Zaikovski, K.I. Zamaraev, Formation of unsual liquid-like FeC particles and dynamics of their nehavior on amorphous carbon surface at 920-1170 K. Dkl. Akad. Nauk. 329, 744 (1993)

142. M.S. Dresselhaus, G. Dresselhaus, P.C. Eklund, Science of Fullerenes and Carbon Nanotubes (Academic Press, San Diego, 1996)

143. V.L. Kutnetsov, Y.V. Butenko, Diamond phase transitions at nanoscale, in Ultrananocrystalline Diamond: Synthesis, Properties and Applications, 2nd edn. ed. by O. Shenderova, D.M. Gruen (Elsevier, 2012)

144. Y.V. Butenko, S. Krishnamurthy, A.K. Chakraborty, V.L. Kuznetsov, V.R. Dhanak, M.R.C. Hunt, L. Scaroniller, L. Šiller, Photoemission study of onionlike carbons produced by annealing nanodiamonds. Phys. Rev. B 71(7), 75420 (2005). doi:10.1103/PhysRevB.71.075420

145. D. Pech, M. Brunet, H. Durou, P.H. Huang, V. Mochalin, Y. Gogotsi, Ultra-high-power micrometre-sized supercapacitors based on onion-like carbon. Nat. Nanotechnol. 5, 651-654 (2010). doi:10.1038/NNANO.2010.162 
146. O. Shenderova, C. Jones, V. Borjanovic, S. Hens, G. Cunningham, S. Moseenkov, Detonation nanodiamond and onion-like carbon: applications in composites. Phys. Stat. Sol. A 205(9), 2245-2251 (2008). doi:10.1002/pssa.200879706

147. O. Shenderova, T. Tyler, V. Borjanovic, G. Cunningham, M. Ray, J. Walsh, M. Casulli, Nanodiamond and onion-like carbon polymer nanocomposites. Diam. Relat. Mater. 16(9), 1213-1217 (2007). doi:10.1016/S09259635(07)00337-8

148. V.L. Kutnetsov, A.L. Chuvilin, Y.V. Butenko, I.L. Malkov, V.M. Titov, Onion-like carbon from ultradisperse diamond. Chem. Phys. Lett. 222(4), 343-348 (1994). doi:10.1016/0009-2614(94)87072-1

149. F. Fugaciu, H. Hermann, G. Seifert, Concentric-shell fullerenes and diamond particles: a molecular-dynamics study. Phys. Rev. B 60(15), 10711-10714 (1999). doi:10.1103/ PhysRevB.60.10711

150. J.Y. Raty, G. Galli, C. Bostedt, T.W. van Buuren, L.J. Terminello, Quantum confinement and fullerenelike surface reconstructions in nanodiamonds. Phys. Rev. Lett. 90(3), 37401 (2003). doi:10.1103/PhysRevLett.90.037401

151. V.L. Kuznetsov, I.L. Zilberberg, Y.V. Butenko, A.L. Chuvilin, B. Segall, Theoretical study of the formation of closed curved graphite-like structures during annealing of diamond surface. J. Appl. Phys. 86(2), 863 (1999). doi:10.1063/1.370816

152. Y.V. Butenko, V.L. Kuznetsov, A.L. Chuvilin, V.N. Kolomiichuk, S.V. Stankus, R.A. Khairulin, The kinetics of the graphitization of dispersed diamonds at low temperatures. J. Appl. Phys. 88(7), 4380-4388 (2000). doi:10.1063/1.1289791

153. G. Davies, T. Evans, Graphitization of diamond at zero temperature and a high pressure. Proc. R. Soc. 328(1574), 413-427 (1972). doi:10.1098/rspa.1972.0086

154. D.S. Su, N.I. Maksimova, G. Mestl, V.L. Kuznetsov, V. Keller, R. Schlogl, N. Keller, Oxidative dehydrogenation of ethylbenzene to styrene over ultra-dispersed diamond and onion-like carbon. Carbon 45(11), 2145-2151 (2007). doi:10.1016/j.carbon.2007.07.005

155. K. Xu, Q. Xue, A new method for deaggregation of nanodiamond from explosive detonation: graphitizationoxidation method. Phys. Solid State 46(4), 649-650 (2004). doi:10.1134/1. 1711442

156. O.E. Anderson, B.L.V. Prasad, H. Sato, T. Enoki, Y. Hishiyama, Y. Kaburagi, M. Yoshikawa, S. Bandow, Structure and electronic properties of graphite nanoparticles. Phys. Rev. B 58(24), 16387-16395 (1998)

157. J. Qian, C. Pantea, J. Huang, T.W. Zerda, Y. Zhao, Graphitization of diamond powders of different sizes at high pressure-high temperature. Carbon 42(12-13), 2691-2697 (2004). doi:10.1016/j.carbon.2004.06.017

158. J. Cebik, J.K. McDonough, F. Peerally, R. Medrano, I. Neitzel, Y. Gogotsi, S. Osswald, Raman spectroscopy study of the nanodiamond-to-carbon onion transformation. Nanotechnology 24(20), 205703 (2013). doi: $10.1088 / 0957-4484 / 24 / 20 / 205703$

159. A. Panich, A.I. Shames, N.A. Sergeev, M. Olszewski, J.K. McDonough, V.N. Mochalin, Y. Gogotsi, Nanodiamond graphitization: a magnetic resonance study. J. Phys. Cond. Matter 25 (24), 245303 (2013). doi:10.1088/0953-8984/25/24/245303

160. Z. Markovic, V. Trajkovic, Biomedical potential of the reactive oxygen species generation and quenching by fullerenes (C60). Biomaterials 29(26), 3561-3573 (2008). doi:10.1016/j. biomaterials.2008.05.005

161. K. Yang, J. Wan, S. Zhang, B. Tian, Y. Zhang, Z. Liu, The influence of surface chemistry and size of nanoscale graphene oxide on photothermal therapy of cancer using ultra-low laser power. Biomaterials 33(7), 2206-2214 (2012). doi:10.1016/j.biomaterials.2011.11.064

162. C. Portet, G. Yushin, Y. Gogotsi, Electrochemical performance of carbon onions, nanodiamonds, carbon black and multiwalled nanotubes in electrical double layer capacitors. Carbon 45(13), 2511-2518 (2007). doi:10.1016/j.carbon.2007.08.024

163. J. Zang, Y. Wang, L. Bian, J. Zhang, F. Meng, Y. Zhao, S. Ren, X. Qu, Surface modification and electrochemical behaviour of undoped Nanodiamonds. Electrochem. Acta 72, 68-73 (2012). doi:10.1016/j.electacta.2012.03.169

164. G. Su, H. Zhou, Q. Mu, Y. Zhang, L. Li, P. Jiao, G. Jiang, B. Yan, Effective surface charge density determines the electrostatic attraction between nanoparticles and cells. J. Phys. Chem. C 116(8), 4993-4998 (2012). doi:10.1021/jp211041m

165. Y.Y. Liu, H. Miyoshi, M. Nakamura, Nanomedicine for drug delivery and imaging: a promising avenue for cancer therapy and diagnosis using targeted functional nanoparticles. Int. J. Cancer 120(12), 2527-2537 (2007). doi:10.1002/ijc.22709

166. A.S. Barnard, Self-assembly in nanodiamond agglutinates. J. Mater. Chem. 18(34), $4038-4041$ (2008). doi:10.1039/b809188a

167. E.D. Eidelman, V.I. Siklitsky, L.V. Sharonova, A stable suspension of single ultrananocrystalline diamond particles. Diam. Relat. Mater. 14(11-12), 1765-1769 (2005). doi:10.1016/j.diamond.2005.08.057

168. E. Osawa, Recent progress and perspectives in single-digit nanodiamond. Diam. Relat. Mater. 16(12), 20182022 (2007). doi:10.1016/j.diamond.2007.08.008

169. A. Pentecost, S. Gour, V. Mochalin, I. Knoke, Y. Gogotsi, Deaggregation of nanodiamond powders using saltand sugar-assisted milling. ACS Appl. Mater. Interfaces 2(11), 3289-3294 (2010). doi:10.1021/am100720n

170. R.J. Hunter, Zeta Potential in Colloids Science (Academic Press, New York, 1981)

171. T.M. Riddick, Zeta-Meter Operating Manual ZM-75 (Zeta-Meter Inc, New York, 1968). 
172. A.V. Delgado, F. González-Caballero, R.J. Hunter, L.K. Koopal, J. Lyklema, Measurement and interpretation of electrokinetic phenomena (IUPAC technical report). Pure Appl. Chem. 77(10), 1753-1805 (2005). doi:10.1351/pac200577101753

173. M. Ozawa, M. Inakuma, M. Takahashi, F. Kataoka, A. Krueger, E. Osawa, Preparation and behavior of brownish, clear nanodiamond colloids. Adv. Mater. 19(9), 1201-1206 (2007). doi:10.1002/adma.200601452

174. V.N. Mochalin, I. Neitzel, B. Etzold, A.M. Peterson, G. Palmese, Y. Gogotsi, Covalent incorporation of aminated nanodiamond into an epoxy polymer network. ACS Nano 5(9), 7494-7502 (2011). doi:10.1021/nn2024539

175. N. Gibson, O. Shenderova, T.J.M. Luo, S. Moseenkov, V. Bondar, A. Puzyr, K. Purtov, Z. Fitzgerald, D.W. Brenner, Colloidal stability of modified nanodiamond particles. Diam. Relat. Mater. 18(4), 620-626 (2009). doi:10.1016/j.diamond.2008.10.049

176. K. Kokubo, K. Matsubayashi, H. Tategaki, H. Takada, T. Oshima, Facile synthesis of highly water-soluble fullerenes more than half-covered by hydroxyl groups. ACS Nano 2(2), 327-333 (2008). doi: $10.1021 / \mathrm{nn} 700151 \mathrm{z}$

177. Y.F. Li, C.I. Hung, C.C. Li, W. Chin, B.Y. Wei, W.K. Hsu, A gas-phase hydrophilization of carbon nanotubes by xenon excimer ultraviolet irradiation. J. Mater. Chem. 19(37), 6761-6765 (2009). doi:10.1039/b905995d

178. L. Pospíšil, M. Gál, M. Hromadová, J. Bulícková, V. Kolivoška, J. Cvacka, K. Nováková, L. Kavan, M. Zukalová, L. Dunsch, Search for the form of fullerene C(60) in aqueous medium. Phys. Chem. Chem. Phys. 12(42), 14095-14101 (2010). doi:10.1039/c0cp00986e

179. H.A. Girard, S. Perruchas, C. Gesset, M. Chaigneau, L. Vieille, J.C. Arnault, P. Bergonzo, J. P. Boilot, T. Gacoin, Electrostatic grafting of diamond nanoparticles: a versatile route to nanocrystalline diamond thin films. ACS Appl. Mater. Interfaces 1(12), 2738-2746 (2009). doi:10.1021/am900458g

180. J. Hees, A. Kriele, O.A. Williams, Electrostatic self-assembly of diamond nanoparticles. Chem. Phys. Lett. 509(1-3), 12-15 (2011). doi:10.1016/j.cplett.2011.04.083

181. C.C. Li, C.L. Huang, Preparation of clear colloidal solutions of detonation nanodiamond in organic solvents. Colloids Surf. A Physicochem. Eng. Asp. 353(1), 52-56 (2010). doi:10. 1016/j.colsurfa.2009.10.019

182. A.I. Shames, A.M. Panich, V.Y. Osipov, A.E. Aleksenskiy, A.Y. Vul', T. Enoki, K. Takai, Structure and magnetic properties of detonation nanodiamond chemically modified by copper. J. Appl. Phys. 107(1), 014318 (2010). doi:10.1063/1.3273486

183. C. Gaillard, H.A. Girard, C. Falck, V. Paget, V. Simic, N. Ugolin, P. Bergonzo, S. Chevillard, J.C. Arnault, Peptide nucleic acid-nanodiamonds: covalent and stable conjugates for DNA targeting. RSC Adv. 4(7), 35663572 (2014). doi:10.1039/C3RA45158E

184. E. Fuente, J.A. Menendez, D. Suarez, M.A. Montes-Moran, Basic surface oxides on carbon materials: a global view. Langmuir 19(8), 3505-3511 (2003). doi:10.1021/la026778a

185. M.A. Montes-Moran, D. Suarez, J.A. Menendez, E. Fuente, On the nature of basic sites on carbon surfaces: an overview. Carbon 42(7), 1219-1225 (2004). doi:10.1016/j.carbon.2004. 01.023

186. C. Leon, J.M. Solar, V. Calemma, L.R. Radovic, Evidence for the protonation of basal-plane sites on carbon. Carbon 30(5), 797-811 (1992). doi:10.1016/0008-6223(92)90164-R

187. V.L. Kuznetsov, Y.V. Butenko, A.L. Chuvilin, A.I. Romanenko, A.V. Okotrub, Electrical resistivity of graphitized ultra-disperse diamond and onion-like carbon. Chem. Phys. Lett. 336(5-6), 397-404 (2001). doi:10.1016/S0009-2614(01)00135-X

188. S. Biniak, G. Szymanski, J. Siedlewskia, A. Swiatkowskib, The characterization of activated carbons with oxygen and nitrogen surface groups. Carbon 35(12), 1799-1810 (1997). doi:10. 1016/S0008-6223(97)00096-1

189. A. Krueger, J. Stegk, Y.J. Liang, L. Lu, G. Jarre, Biotinylated nanodiamond: simple and efficient functionalization of detonation diamond. Langmuir 24(8), 4200-4204 (2008). doi:10.1021/la703482v

190. V. Chakrapani, J.C. Angus, A.B. Anderson, S.D. Wolter, B.R. Stoner, G.U. Sumanasekera, Charge transfer equilibria between diamond and an aqueous oxygen electrochemical redox couple. Science 318(5855), 14241430 (2007). doi:10.1126/science. 1148841

191. T. Kondo, I. Neitzel, V.N. Mochalin, J. Urai, M. Yuasa, Y. Gogotsi, Electrical conductivity of thermally hydrogenated nanodiamond powders. J. Appl. Phys. 113(21), 214307 (2013). doi:10.1063/1.4809549

192. K.K. Liu, C.C. Wang, C.L. Cheng, J.I. Chao, Endocytic carboxylated nanodiamond for the labeling and tracking of cell division and differentiation in cancer and stem cells. Biomaterials 30(26), 4249-4259 (2009). doi:10.1016/j.biomaterials.2009.04.056

193. Y. Yuan, X. Wang, G. Jia, J.H. Liu, T. Wang, Y. Gu, S.T. Yang, S. Zhen, H. Wang, Y. Liu, Pulmonary toxicity and translocation of nanodiamonds in mice. Diam. Relat. Mater. 19(4), 291-299 (2009). doi:10.1016/j.diamond.2009.11.022

194. N. Mohan, C.S. Chen, H.H. Hsieh, Y.C. Wu, H.C. Chang, In vivo imaging and toxicity assessments of fluorescent nanodiamonds in Caenorhabditis elegans. Nano Lett. 10(9), 3692-3699 (2010). doi: $10.1021 / \mathrm{nl} 1021909$

195. V. Vaijayanthimala, P.Y. Cheng, S.H. Yeh, K.K. Liu, C.H. Hsiao, J.I. Chao, H.C. Chang, The long-term stability and biocompatibility of fluorescent nanodiamond as an in vivo contrast agent. Biomaterials 33(31), 7794-7802 (2012). doi:10.1016/j.biomaterials.2012.06.084

196. S.J. Yu, M.W. Kang, H.C. Chang, K.M. Chen, Y.C. Yu, Bright fluorescent nanodiamonds: no photobleaching 
and low cytotoxicity. J. Am. Chem. Soc. 127(50), 17604-17605 (2005). doi:10.1021/ja0567081

197. Y. Xing, W. Xiong, L. Zhu, E. Osawa, S. Hussin, L. Dai, DNA damage in embryonic stem cells caused by nanodiamonds. ACS Nano 5(3), 2376-2384 (2011). doi:10.1021/nn200279k

198. J.A. Sergent, V. Paget, S. Chevillard, Toxicity and genotoxicity of nano-SiO2 on human epithelial intestinal HT-29 cell line. Ann. Occup. Hyg. 56(5), 622-630 (2012). doi:10.1093/ annhyg/mes005

199. L.J. Mah, A. El-Osta, T.C. Karagiannis, gammaH2AX: a sensitive molecular marker of DNA damage and repair. Leukemia 24(4), 679-686 (2010). doi: 10.1038/leu.2010.6

200. A.M. Schrand, J.B. Lin, S.C. Hens, S.M. Hussain, Temporal and mechanistic tracking of cellular uptake dynamics with novel surface fluorophore-bound nanodiamonds. Nanoscale 3 (2), 435-445 (2011). doi:10.1039/c0nr00408a

201. I.P. Chang, K.C. Hwang, C.S. Chiang, Preparation of fluorescent magnetic nanodiamonds and cellular imaging. J. Am. Chem. Soc. 130(46), 15476-15481 (2008). doi:10.1021/ ja804253y

202. U. Maitra, A. Jain, S.J. George, C.N. Rao, Tunable fluorescence in chromophore-functionalized nanodiamond induced by energy transfer. Nanoscale 3(8), 3192-3197 (2011). doi:10.1039/c1nr10295h

203. Q. Zhang, V.N. Mochalin, I. Neitzel, I.Y. Knoke, J. Han, C.A. Klug, J.G. Zhou, P.I. Lelkes, Y. Gogotsi, Fluorescent PLLA-nanodiamond composites for bone tissue engineering. Biomaterials 32(1), 87-94 (2011). doi:10.1016/j.biomaterials.2010.08.090

204. X.Q. Zhang, M. Chen, R. Lam, X.Y. Xu, E. Osawa, D. Ho, Polymer-functionalized nanodiamond platforms as vehicles for gene delivery. ACS Nano 3(9), 2609-2616 (2009). doi:10.1021/nn900865g

205. H.D. Wang, Q. Yang, C.H. Niu, I. Badea, Protein-modified nanodiamond particles for layer-by-layer assembly. Diam. Relat. Mater. 20(8), 1193-1198 (2011). doi:10.1016/j.diamond. 2011.06.015

206. Y.K. Tzeng, O. Faklaris, B.M. Chang, Y. Kuo, J.H. Hsu, H.C. Chang, Superresolution imaging of albuminconjugated fluorescent nanodiamonds in cells by stimulated emission depletion. Angew Chem. Int. Ed Eng. 50(10), 2262-2265 (2011). doi:10.1002/anie.201007215

207. C.Y. Cheng, E. Perevedentseva, J.S. Tu, P.H. Chung, C.L. Cheng, K.K. Liu, J.I. Chao, P.H. Chen, C.C. Chang, Direct and in vitro observation of growth hormone receptor molecules in A549 human lung epithelial cells by nanodiamond labeling. Appl. Phys. Lett. 90(16), 163903 (2007). doi:10.1063/1.2727557

208. D.T. Tran, V. Vermeeren, L. Grieten, S. Wenmackers, P. Wagner, J. Pollet, K.P. Janssen, L. Michiels, J. Lammertyn, Nanocrystalline diamond impedimetric aptasensor for the label-free detection of human IgE. Biosens. Bioelectron. 26(6), 2987-2993 (2011). doi:10.1016/j.bios. 2010.11.053

209. A.H. Smith, E.M. Robinson, X.Q. Zhang, E.K. Chow, Y. Lin, E. Osawa, J. Xi, D. Ho, Triggered release of therapeutic antibodies from nanodiamond complexes. Nanoscale 3(7), 2844 (2011). doi:10.1039/c1nr10278h

210. A. Barras, J. Lyskawa, S. Szunerits, P. Woisel, R. Boukherroub, Direct functionalization of nanodiamond particles using dopamine derivatives. Langmuir 27, 12451-12457 (2011). doi:10.1021/la202571d

211. R.A. Shimkunas, E. Robinson, R. Lam, S. Lu, X. Xu, X.Q. Zhang, H. Huang, E. Osawa, D. Ho, Nanodiamondinsulin complexes as pH-dependent protein delivery vehicles. Biomaterials 30(29), 5720-5728 (2009). doi:10.1016/j.biomaterials.2009.07.004

212. E. Perevedentseva, P.J. Cai, Y.C. Chiu, C.L. Cheng, Characterizing protein activities on the lysozyme and nanodiamond complex prepared for bio applications. Langmuir 27(3), 1085-1091 (2011). doi:10.1021/la103155c

213. T.T.B. Nguyen, H.C. Chang, V.W.K. Wu, Adsorption and hydrolytic activity of lysozyme on diamond nanocrystallites. Diam. Relat. Mater. 16(4-7), 872-876 (2007). doi:10.1016/j. diamond.2007.01.030

214. V.S. Bondar, I.O. Pozdnyakova, A.P. Puzyr, Applications of nanodiamonds for separation and purification of proteins. Phys. Solid State 46(4), 758-760 (2004). doi:10.1134/1.1711468

215. R. Lam, M. Chen, E. Pierstorff, H. Huang, E. Osawa, D. Ho, Nanodiamond-embedded microfilm devices for localized chemotherapeutic elution. ACS Nano 2(10), 2095-2102 (2008). doi:10.1021/nn800465x

216. H. Huang, E. Pierstorff, E. Osawa, D. Ho, Active nanodiamond hydrogels for chemotherapeutic delivery. Nano Lett. 7(11), 3305-3314 (2007). doi:10.1021/n1071521o

217. M. Chen, X.Q. Zhang, H.B. Man, R. Lam, E.K. Chow, D. Ho, Nanodiamond vectors functionalized with polyethylenimine for siRNA delivery. J. Phys. Chem. Lett. 1(21), 3087-3095 (2010). doi:10.1021/jz1013278

218. H. Huang, E. Pierstorff, E. Osawa, D. Ho, Protein-mediated assembly of nanodiamond hydrogels into a biocompatible and biofunctional multilayer nanofilm. ACS Nano 2(2), 203-212 (2008). doi:10.1021/nn7000867

219. J. Tisler, R. Reuter, A. Lammle, F. JElezko, G. Balasubramanian, P.R. Hemmer, F. Reinhard, J. Wrachtrup, Highly efficient FRET from single NV center in nanodiamonds to single organic molecule. ACS Nano 5(10), 7893-7898 (2011). doi:10.1021/nn2021259

220. N. Mohan, Y.K. Tzeng, L. Yang, Y.Y. Chen, Y.Y. Hui, C.Y. Fang, H.C. Chang, Sub-20-nm fluorescent nanodiamonds as photostable biolabels and fluorescence resonance energy transfer donors. Adv. Mater. 22(7), 843-847 (2010). doi:10.1002/adma.200901596

221. V. Grichko, T. Tyler, V.I. Grishko, O. Shenderova, Nanodiamond particles forming photonic structures. Nanotechnology 19(22), 225201 (2008). doi:10.1088/0957-4484/19/22/225201

222. O. Faklaris, V. Joshi, T. Irinopoulou, P. Tauc, M. Sennour, H. Girard, C. Gesset, J.C. Arnault, A. Thorel, J.P. Boudou, P.A. Curmi, F. Treussart, Photoluminescent diamond nanoparticles for cell labeling: study of the uptake mechanism in mammalian cells. ACS Nano 3(12), 3955-3962 (2009). doi:10.1021/nn901014j 
223. L.P. McGuinness, Y. Yan, A. Stacey, D.A. Simpson, L.T. Hall, D. Maclaurin, S. Prawer, P. Milvaney, J. Wrachtrup, F. Caruso, R.E. Scholten, L.C.L. Hollenberg, Quantum measurement and orientation tracking of fluorescent nanodiamonds inside living cells. Nat. Nanotech. 6, 358-363 (2011). doi:10.1038/nnano.2011.64

224. S.C. Hens, G. Cunningham, T. Tyler, S. Moseenkov, V. Kuznetsov, O. Shenderova, Nanodiamond bioconjugate probes and their collection by electrophoresis. Diam. Relat. Mater. 17(11), 1858-1866 (2008). doi:10.1016/j.diamond.2008.03.020

225. V.N. Mochalin, Y. Gogotsi, Wet chemistry route to hydrophobic blue fluorescent nanodiamond. J. Am. Chem. Soc. 131(13), 4594-4595 (2009). doi:10.1021/ja9004514

226. L.M. Manus, D.J. Mastarone, E.A. Waters, X.Q. Zhang, E.A. Schultz-Sikma, K.W. MacRenaris, D. Ho, T.J. Meade, Gd(III)-nanodiamond conjugates for MRI contrast enhancement. Nano Lett. 10(2), 484-489 (2010). doi: $10.1021 / \mathrm{nl} 903264 \mathrm{~h}$

227. S.S. Tinkle, Maximizing safe design of engineered nanomaterials: the NIH and NIEHS research perspective. Wiley Interdiscip Rev Nanomed Nanobiotechnol 2(1), 88-98 (2010). doi:10.1002/wnan.63

228. D.B. Warheit, P.J.A. Borm, C. Hennes, J. Lademann, Testing strategies to establish the safety of nanomaterials: conclusions of an ECETOC workshop. Inhal Toxicol. 19(8), 631-643 (2007). doi:10.1080/08958370701353080 